
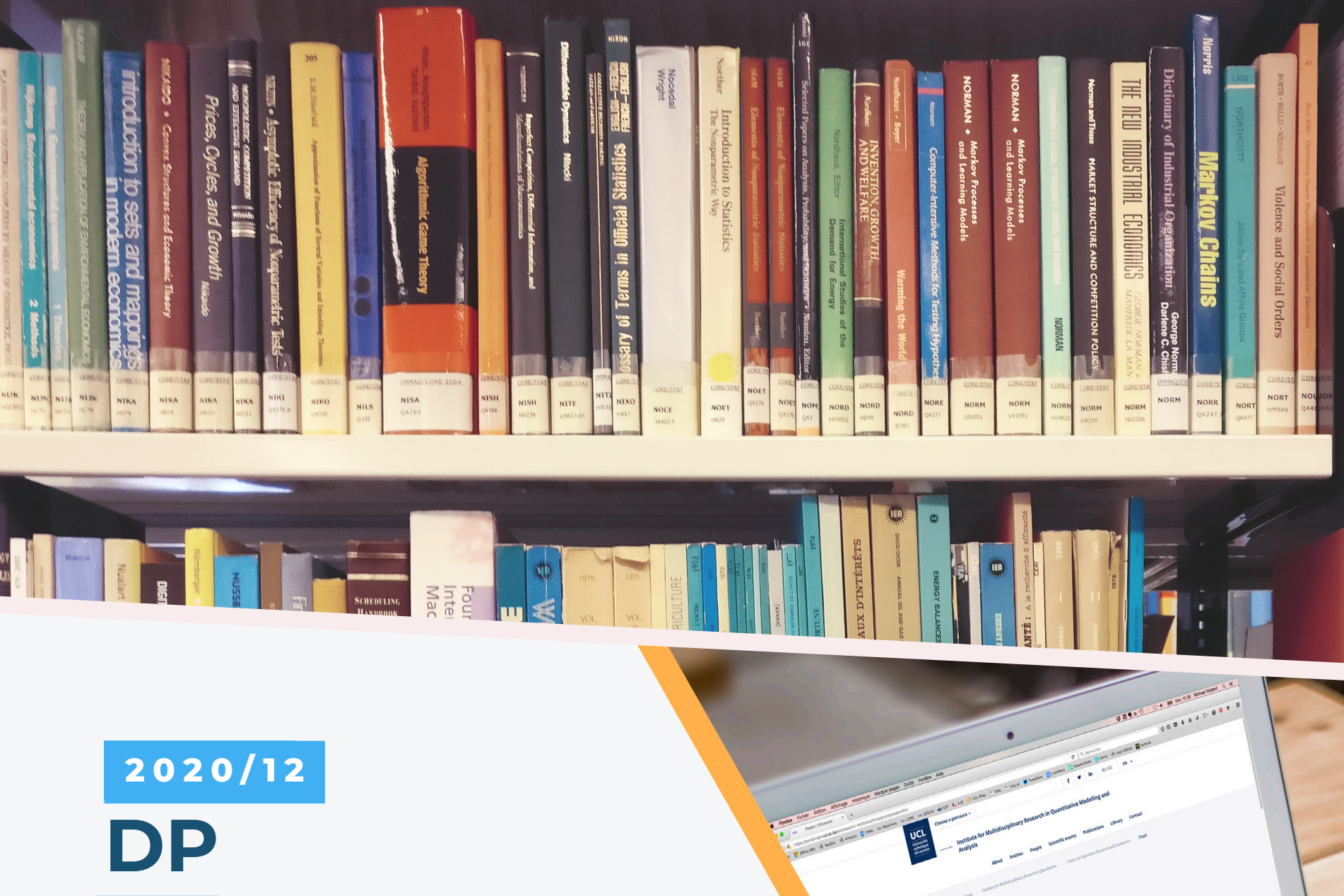

Jean Hindriks and Valerio Serse

The incidence of VAT

reforms in electricity markets:

Evidence from Belgium

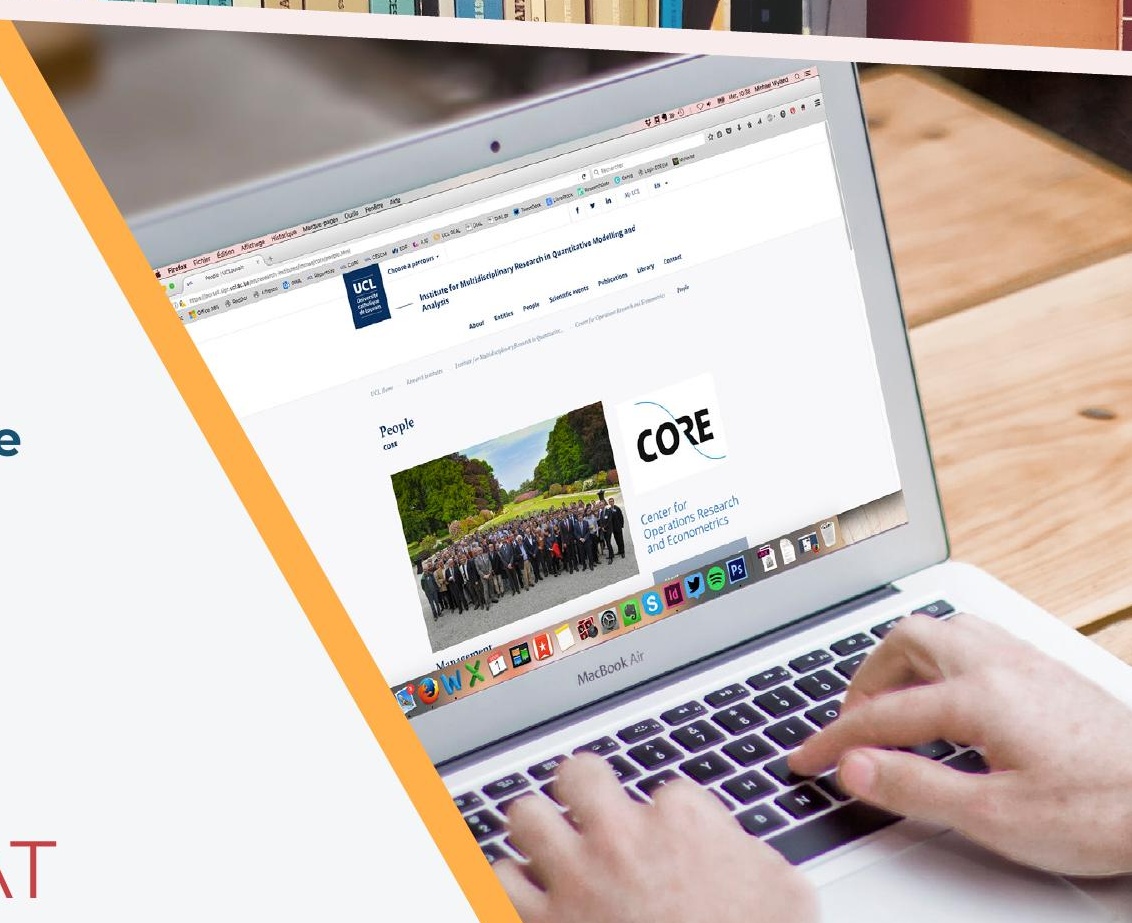




\section{CORE}

Voie du Roman Pays 34, L1.03.01

B-1348 Louvain-la-Neuve

Tel (32 10) 474304

Email: immaq-library@uclouvain.be

https://uclouvain.be/en/research-institutes/

lidam/core/discussion-papers.html 


\title{
The Incidence of VAT Reforms in Electricity Markets: Evidence from Belgium*
}

\author{
Jean Hindriks ${ }^{\dagger}$ and Valerio Serse
}

This version: April 2020

\begin{abstract}
In April 2014, the Belgian government reduced the VAT rate on the electricity price from $21 \%$ to $6 \%$. In September 2015, however, this tax cut was repealed, and the VAT rate was reinstated to $21 \%$. This paper investigates the impact of such temporary exogenous VAT reform on the Belgian electricity market. We study both the pass-through of the VAT reform to electricity prices and the effect of this (exogenous) price change on electricity consumption. We estimate the VAT pass-through by a difference-in-differences approach using business electricity prices (not subject to VAT) as a control group. To estimate the impact of the VAT change on demand, we perform an event study on the electricity flowed monthly over the grid at the network operator level. Our findings reveal that both the tax cut and the tax hike were entirely shifted to the electricity price (i.e., 100\%). Exploiting different sources of price variation, our results reveal a price elasticity of residential demand for electricity between -0.09 and -0.17 . Interestingly, we also find that consumption reacted quickly and symmetrically to the VAT cut and the subsequent VAT hike.
\end{abstract}

JEL classification: H21, H22, H23, Q41, Q48.

Keywords: tax incidence, VAT reform, demand elasticity, electricity markets.

\footnotetext{
${ }^{*}$ We are grateful to the CREG for the support on data collection and in particular to Christine Cobut, Natalie Cornelis and Laurent Jacquet. We have benefited from very useful comments and suggestions by Paul Belleflamme, Olivier De Groote, Axel Gautier, Anthony Papavasiliou, and various seminar participants at the Economics School of Louvain and Toulouse School of Economics. The financial support from the FNRS is gratefully acknowledged.

$\uparrow$ CORE, Université catholique de Louvain, e-mail: jean.hindriks@uclouvain.be.

*CORE, Université catholique de Louvain, FNRS-FRESH grant holder, e-mail : valerio.serse@uclouvain.be.
} 


\section{Introduction}

In April 2014, the Belgian government reduced the value-added tax (VAT) rate on the electricity price from $21 \%$ to $6 \%$. In September 2015, this tax cut was repealed, and the VAT rate reverted to $21 \%$. This paper investigates the impact of such temporary VAT reform on the Belgian electricity market. The aim is to study the effect of this tax reform on electricity price and consumption. The results of this analysis shed light on the tax incidence in the electricity market, and the price elasticity of electricity demand. The tax reform and resulting price change provide an excellent natural experiment, as they are exogenous to households' consumption behavior. We also provide novel evidence on the possible asymmetry in tax incidence following the tax reform. Indeed, the VAT reforms involved first a tax cut to $6 \%$, followed by a tax hike to $21 \%$. This provides a perfect setting to test for symmetry in the price and consumption responses to tax cuts and tax hikes within the time interval April 2014-September 2015.

The quality of the tax incidence analysis depends on the exogeneity of the tax reforms. In a Royal Decree of 21 March 2014, it was decided to cut the VAT rate on electricity supply to residential customers from $21 \%$ to $6 \%$ conditional on the evaluation of this tax reform by September 2015. The reform was part of the "competitiveness and employment pact" of the government Di-Rupo. The VAT cut was in fact a social measure from a socialist government intended to benefit the low-income households, and its budgetary cost was perceived as limited, given its impact on wage and social security benefit indexation. Indeed, the VAT cut was expected to lower the inflation rate, which given the Belgian automatic indexation, translates into a reduction of the wage costs and social security benefits. In October 2014, the center-right government Michel replaced the socialist government. The government Michel enacted the Plan Bureau to estimate the budgetary cost of the reform. The inflation rate was reduced by $0.4 \mathrm{pp}$, indexation was postponed by four months, and the net budgetary cost of the reform was estimated at 536 million euros in 2015 (BFP, 2015).

Then the government Michel proposed in July 2015 a new "tax shift" plan. This plan organized a broad shifting of tax base from labor to consumption as part of a strategy to lower wage costs and promote employment. The tax shift plan involved the VAT rate increase from $6 \%$ to $21 \%$ in September 2015. The VAT reinstatement was indeed a political move from a liberal coalition to undo the reform from the socialist government. Therefore, the two successive VAT reforms can be seen as exogenous shocks motivated by political decisions from two different governments, with no interaction with the electricity market. 
The structure of the electricity market is rather specific. The retail market is competitive, whereas transmission and distribution markets are regulated by the Belgian energy authority, the Commission for Electricity and Gas Regulation (CREG). This means that energy producers and service providers (retailers) can react freely to a variation in VAT. Firstly, we study whether these operators entirely shifted this temporary VAT cut to the electricity price paid by households or retained a part of it in their price. We estimate the VAT pass-through to the electricity price by employing a difference-in-differences strategy. We use as a control group the electricity price paid by professional consumers (firms) to assess the impact of the temporary VAT reform of the electricity price paid by households. The assumption is that the electricity price for households would have followed the same trend as the electricity price for firms in case the reform did not occur. The VAT is charged only on final consumption by households but not on intermediate consumption by firms and professional consumers.

The results show that the VAT cut was entirely shifted to the household electricity price. Producers and service providers passed the tax cut entirely to the benefit of households, with both regulated and unregulated firms reacting similarly. Furthermore, we do not find any asymmetry in tax shifting between the first VAT cut to $6 \%$ and the subsequent VAT hike to $21 \%$. These findings highlight that the tax change is entirely shifted to electricity prices. If this result is typical for the regulated component of the electricity bill (transmission and distribution), it is less so for the unregulated components (service providers and energy producers). Given that tax changes are perfectly shifted on the electricity price, these can have a significant impact on both electricity consumption and tax revenues.

We then estimate the impact of the VAT reform on the electricity demand of Belgian households. We study the monthly consumption of electricity at the network distributor level, controlling for changes in other determinants of energy use during the period. We find that the VAT cut from $21 \%$ to $6 \%$ generated around a $2 \%$ increase in demand for electricity. Exploiting different sources of price variation, our results reveal a price elasticity of residential demand for electricity between -0.09 and -0.17 . This measure, however, can also vary across regions. We provide novel evidence about the symmetry in the consumption response to price cuts and price hikes. Consumption changes to the same extent (albeit in a different direction) after a price cut and a price hike of the same magnitude. This finding has important implications for price-based climate policies, as it indicates that price hikes through taxation can be effective in reducing energy use. 
Lastly, we show that consumers responded quickly to the VAT reform, increasing their consumption one month after the VAT cut. This evidence contrasts with the existing literature, which suggests that consumers respond slowly to changes in electricity prices. ${ }^{1}$ The VAT reform was announced early in the media, and the pass-through was perfect, making the reform more salient. Such salience of the tax reform may induce consumers to react more quickly compared to other price changes (Chetty, Looney, \& Kroft, 2009). We also find that the increase in electricity demand is mostly concentrated in sunnier and warmer periods when energy is less needed for both heating and home lighting. This result can cast doubts on the welfare effect of such a policy, given that electricity production involves negative externalities from higher $\mathrm{CO} 2$ emissions. $^{2}$

The paper is organized as follows. In section 2, we review the existing literature and identify our contribution. Section 3 describes the structure of the Belgian electricity market. Section 4 presents some theoretical background on VAT incidence and market structure. In section 5, we describe the data used. Section 6 presents the models and shows the results of the empirical analysis. Section 7 shows the results of some robustness checks. Section 8 concludes.

\section{Background Literature}

This work contributes to the literature on VAT incidence by providing novel insights in the context of electricity markets. The empirical research has mostly focused on the incidence of excise taxes rather than sales taxes and VAT. ${ }^{3}$ Recent studies have found that the cost of emission permits in Europe is almost entirely shifted to electricity prices (Fabra \& Reguant, 2014; Hintermann, 2016). However, there is a lack of evidence regarding the pass-through of value-added taxes to retail electricity prices. Most studies estimate sales taxes (or VAT) passthrough following a reduced-form approach between prices and tax rates (see, for instance, Poterba, 1996; Besley \& Rosen, 1999). Doyle \& Samphantharak (2008) and Marion \& Muehlegger (2011) study the incidence of sales taxes on fuel in the United States. They both find a pass-through close to unity, which can vary with differences in supply-side conditions.

\footnotetext{
${ }^{1}$ Price elasticity of electricity demand tends to increase over time because energy consumption depends on the stock of the owned appliances. While this is fixed in the short-run, this can be changed in the long-run as a function of the present and expected future prices.

${ }^{2}$ Around the $30 \%$ of the electricity generation in Belgium is based on fossil fuels, mainly natural gas (Eurostat, 2020).

${ }^{3}$ Many works studied excise tax incidence in the context of sodas (Berardi et al., 2016; Cawley \& Frisvold, 2017; Etilé, Lecocq, \& Boizot-Szantai, 2019), cigarettes (Harding, Leibtag, \& Lovenheim, 2012; DeCicca, Kenkel, \& Liu, 2013) and alcoholic beverages (Kenkel, 2005; Shrestha \& Markowitz, 2016; Hindriks \& Serse, 2019).
} 
Doyle \& Samphantharak (2008) also provide some evidence that tax cuts are less than fully shifted to fuel prices.

Carbonnier (2007) studies the VAT incidence of two French reforms decreasing the VAT rate on housing repairing services and new car sales. He finds that both VAT cuts were not entirely shifted to consumer prices. The tax shifting was $77 \%$ for housing repairing services and $53 \%$ for new car sales. He associates such a difference in the VAT pass-through to the higher concentration in the new car sales sector. Kosonen (2015) studies the incidence of the VAT reform on hairdressing services in Finland, which reduced the VAT rate from $22 \%$ to $8 \%$. He finds that hairdressers have only passed half of the VAT reduction to consumer prices. Benedek et al. (2019) review the literature on VAT pass-through in the Eurozone for a wide variety of markets, but they don't consider the one for electricity. They find that the pass-through of the standard VAT rate is usually $100 \%$, while for reduced rates, it is around $30 \%$. Contrary to these findings, we show that the reduction from a standard rate of $21 \%$ to a reduced rate of $6 \%$ was entirely shifted to retail electricity prices.

This literature typically identifies the VAT pass-through by looking at the change in consumer price before and after the VAT reform, while controlling for the price evolution in other markets. ${ }^{4}$ Yet, finding a reliable control group to VAT changes is rather difficult. This is because the VAT affects the whole market to which it is applied. Furthermore, even if the VAT change affects only one sector, there is a risk of a cross-price effect on the closest sectors producing substitute products. We extend this literature by adopting a difference-in-differences approach that uses business prices as a counterfactual scenario. Business prices are not subject to VAT, but share the same cost components with residential prices. Moreover, these two tariffs are not substitutable since households cannot get a business price as residential customers. Our findings suggest that without controlling for business prices, we would have reached the misleading conclusion that the VAT cut was not entirely shifted to consumer prices.

The literature focussing on the price elasticity of electricity demand is instead more substantial, although very few papers are based on quasi-experimental (exogenous) variation in prices. The majority of studies estimate dynamic panel models on state-level data. Labandeira, Labeaga, \& López-Otero (2017) provide an exhaustive review of this literature, showing that the short-run and the long-run demand elasticities are on average -0.21 and -0.67 , respectively. However, a

\footnotetext{
${ }^{4}$ Benedek et al. (2019) use as counterfactual price the one of the same commodity sold in other European countries that did not change their VAT rate. Carbonnier (2007) uses the price index for non-treated industries. While Kosonen (2015) uses the price of other labor intensive services.
} 
limitation of these studies is that they tend to assume that prices are exogenous to consumer demand. Furthermore, it has been shown that estimates of dynamic panel models can vary significantly with the specification used (Alberini \& Filippini, 2011).

Some recent studies exploit quasi-experimental variation in prices to recover the price elasticity of electricity demand. However, those studies do not consider tax change. Ito (2014) estimates the demand response to either average and marginal electricity price variations induced by a discontinuity in electricity service areas in California. He finds that the demand is sensitive to average prices rather than marginal prices, with a demand elasticity of -0.09 four months after the (average) price changes. In our context, we do not disentangle average and marginal prices as the VAT is applied to both the price per $\mathrm{kWh}$ and the fixed fees. Therefore, the VAT reform changes marginal and average prices to the same extent.

Deryugina, MacKay, \& Reif (2020) study the elasticity of residential electricity demand following an exogenous drop in electricity prices due to a municipal aggregation policy in Illinois. The municipal aggregation allowed local communities to select new electricity suppliers on behalf of their residents with the approval of a local referendum. This policy led to a large price decrease in communities that implemented aggregation. They find a demand elasticity that can vary between -0.09 and -0.16 within 6 and 12 months, respectively. Nevertheless, as they only observe a price cut, they cannot check for differences in demand elasticity following a price hike.

Interestingly, our measure for the price elasticity of demand is in keeping with these quasiexperimental studies. In contrast with these studies, however, we find that the demand response to the price change is immediate. This is probably because we are exploiting a price variation that was less complex and more salient for consumers. Given that we do not have a reliable control group for the consumption analysis, we run a placebo test on the evolution of the electricity consumption of SMEs (not subject to VAT). We find that during the VAT cut, the SMEs did not increase electricity demand, contrary to households. Therefore, this is suggesting that our estimates are likely to capture the causal effect of price on demand.

\section{The Belgian Electricity Market}

Electricity markets have a unique structure. Electricity is firstly produced by electricity generators, and it is then transported to end-users. The transport is composed of transmission and distribution networks. Transmission system operators manage the transmission network. They are in charge of transporting electricity over long distances from the generators to the 
distribution network. The distribution network is instead managed by distribution operators, which deliver electricity to the end-users. The electricity is sold to consumers by service providers, who buy it from the generators or produce it themselves. The electricity bill paid by consumers is the sum of the costs of these different operators. As for most countries, electricity transmission in Belgium has regulated tariffs. This means that any change in price for the transmission and distribution of electricity has to be approved ex-ante by the energy regulator (CREG). Downstream, service providers also set their prices freely for the supply of electricity in a competitive market.

Upstream, the energy component of the electricity bill is set freely by producers since the liberalization of the electricity and gas market. This price includes the pure energy component and the green energy component $22.1 \%$ of the total energy component in 2019 or $7.8 \%$ of the total cost of electricity). Between 2013-2017, the government used a "safety net" mechanism to limit the price of the energy component upward. Under this mechanism, energy suppliers can index variable energy prices every three months. The CREG monitors indexing and compares possible price increases with those of consumers of the same type in neighboring countries.

Another important component of the electricity bill is the taxes levied at both federal and regional levels. The shares of the various components may vary depending on the type of customer considered, distribution areas, regions, and suppliers. In this work, we consider the marginal price of electricity. Hence, we consider only those taxes levied per kWh consumed. These include both regional and federal levies, which are also subject to VAT.

\section{VAT incidence and market structure}

Electricity tax is levied on the final supply of electricity to the consumer, and the liability arises at the time the electricity is supplied. The supplier is responsible for payment of the tax and all remunerations. In this paper, we consider the tax incidence analysis of the VAT change for households only (domestic electricity use by contrast to business use). Before we carry out the empirical analysis, let us remind some theoretical features of tax incidence depending on the market structure and the type of taxes (ad-valorem versus specific taxes). Specific tax is a tax per unit $(\mathrm{kWh})$ for electricity supplied. The ad valorem tax, such as the VAT, is a tax per unit of the price ( $€$ cents) for electricity supplied.

The two types of taxation can be represented as follows. Let $q$ denotes the consumer price and $p$ the producer price. A specific tax rate $t$ induces a consumer price of $q=p+t$. An ad valorem tax rate of $\tau$ induces a consumer price of $q=(1+\tau) p$. Tax incidence measures the 
impact of a change in the tax rate on the consumer price. Fixing the ad valorem tax rate at $\tau=$ $t / p$ implies that $q=p+t=(1+\tau) p$ which induces the same consumer price $q$ and, therefore, the same consumption $x$. Both taxes would then raise the same tax revenue. Indeed under ad valorem tax, the revenue raised is $R=\tau p x$ which using $\tau=t / p$ is equivalent to $R=$ $t x$, which is the revenue raised under the specific tax. The market equilibrium determines the incidence of the tax on producer and consumer prices by equating demand and supply $D(p)=$ $S(q)=x$.

Figure 1: Tax incidence under perfect competition

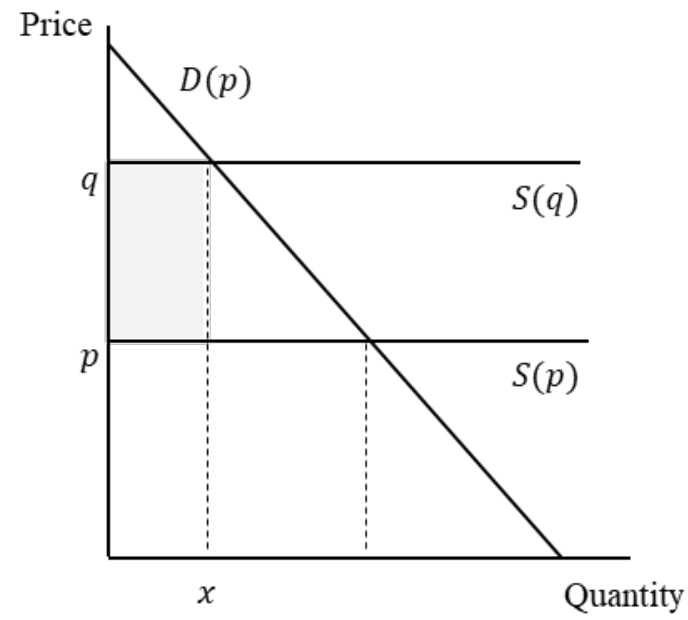

Specific tax

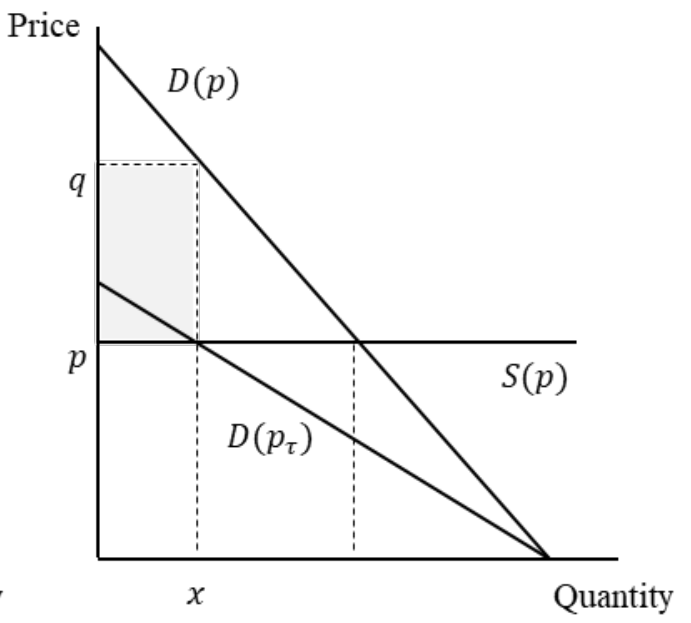

Ad valorem tax

(Tax revenue in shaded area)

Under imperfect competition, the equivalence breaks down, and ad valorem tax dominates specific tax in the sense that ad valorem tax raises more revenue for the same consumer price than the specific tax. The reason is that under imperfect competition, the producers are no longer price takers, but they can raise the price above the competitive price by limiting the supply. By taxing price directly rather than quantity, ad valorem taxation will limit this market power. To see this, let us consider a monopole facing a demand $x(q)$ with a constant unit $\operatorname{cost} c$. The monopoly profit under specific tax rate $t$ is $\Pi=(q-t) x-c x=q x-(c+t) x$. The specific tax is equivalent to increasing the unit cost at a rate $\mathrm{t}$. The ad valorem tax at rate $\tau$ implies that for consumer price $q$, the monopoly receives $p=q / 1+\tau$. From the monopoly's perspective, the specific tax increases cost from $c$ to $c+t$, whereas the ad valorem tax reduces revenue from $q x$ to $q x / 1+\tau$.

Under perfect competition, the supplier perceives no effect on price, and so both taxes are equivalent. However, under imperfect competition, it is no longer valid. With ad valorem 
taxation, monopoly profit is $\prod=q x / 1+\tau-c x=[1 / 1+\tau][q x-(c+\tau c) x]$. The ad valorem tax is equivalent to combining a profit tax at rate $\tau / 1+\tau$ and a specific tax at rate $\tau c$. The profit tax is proportional to profit, and so it does not affect supply. If we set ad valorem tax rate such that $\tau c=t$ the ad valorem tax induces the same consumer price $q$ as the specific tax $t$. But the ad valorem tax raises more revenue than the specific tax since $R=\tau c x+(\tau / 1+$ $\tau) \prod=t x+(t / c+t) \prod>t x$. Thus, the ad valorem tax raises more revenue than the specific tax for the same consumer price. Alternatively, for the same tax revenue, ad valorem tax reduces consumer price compared to a specific tax. Ad valorem tax is superior because it is a tax on the market power (profit margin) of the supplier.

\section{The Data}

The price data used in this study are provided by the Belgian Energy Regulator (CREG). We build a price series for every type of electricity contract. Any service provider can offer electricity contracts to either firms and households. Only households are subject to VAT since firms can fully recover the VAT paid from the VAT received on sales. Most electricity providers in Belgium have different tariffs for different consumption profiles. In this study, we use the price of electricity paid by households with a consumption profile of 3,500 kWh. For firms, we consider the tariff for a consumption profile of 50,000 $\mathrm{kWh}$. We use data from two leading electricity providers in Belgium: Luminus and Electrabel (Engie). We use data from their two most common contracts. These are Luminus Click, Luminus A+, Easy Fixed, and Easy Indexed. Each of these contracts has both the firm and household version. Hence, we consider eight price series of electricity contracts, where prices are expressed in $€$ cent $/ \mathrm{kWh}$.

The total price paid by the client for a given electricity service is the sum of various cost components. These components include the cost of energy, distribution \& transmission, and taxes \& surcharges. Service providers are responsible for the energy supply to the client and bill the energy use. The price for the contracts Luminus Click and Easy Fixed is fixed overtime for a client. This means that once the client signs these contracts, the electricity price for that client is fixed for a given period (this can be from 1 up to 3 years). Even though these prices are fixed for the client who already signed it, they can change monthly for any potential new client (Newcomer contract). The other contracts are instead indexed. Their price can change for both new and old customers according to an indexation formula. The price, however, can be indexed just every quarter, which means that these prices only change three times per year. 
Another price component is the remuneration for the network operators, which are responsible for the distribution and the transmission of the electricity in the grid. These operators are active locally, and their prices can vary over space. In this study, we have data for a total of 23 distribution grid operators. ${ }^{5}$ Although these fees can vary across localities, they do not vary across different service providers and types of electricity contracts. That is, every network operator has to charge the same price to every provider locally. The rest of the bill is composed of federal and local energy taxes. If the contract is designed for a household, it is then applied the VAT to each of these price components. The total monthly electricity price for a client is the sum of all these components. This price can vary across both contracts offered by service providers and local network operators. Table 1 below summarizes the data in our sample, distinguishing between the electricity prices for households and firms during the period of VAT reforms.

Table 1

\begin{tabular}{|c|c|c|c|c|c|c|}
\hline \multicolumn{7}{|c|}{ Summary Statistics - Electricity Price } \\
\hline \multirow[b]{2}{*}{ Price Component } & \multicolumn{2}{|c|}{$\begin{array}{c}21 \% \text { VAT period } \\
(06 / 13-03 / 14)\end{array}$} & \multicolumn{2}{|c|}{$\begin{array}{c}6 \% \text { VAT period } \\
(04 / 14-08 / 15)\end{array}$} & \multicolumn{2}{|c|}{$\begin{array}{c}21 \% \text { VAT period } \\
(09 / 15-03 / 16)\end{array}$} \\
\hline & Households & Firms & Households & Firms & Households & Firms \\
\hline Energy & 7.41 & 6.53 & 6.45 & 6.49 & 6.71 & 5.94 \\
\hline Green Quota $^{6}$ & 1.84 & 1.52 & 1.84 & 1.74 & 2.46 & 2.03 \\
\hline Distribution & 9.92 & 8.25 & 9.09 & 8.61 & 11.77 & 9.74 \\
\hline Transmission & 2.40 & 1.96 & 2.49 & 2.34 & 2.87 & 2.37 \\
\hline $\begin{array}{l}\text { Other Taxes } \\
\text { (VAT excl.) }\end{array}$ & 0.64 & 0.53 & 0.51 & 0.50 & 0.53 & 0.51 \\
\hline Total & 22.21 & 18.80 & 20.38 & 19.68 & 24.35 & 20.59 \\
\hline
\end{tabular}

Notes: Price components are expressed in $€$ cent/kWh. These prices are the average over the contracts and network operators included in the sample. For Household prices, each components includes the VAT.

\footnotetext{
${ }^{5}$ However, in the consumption analysis we drop observation about eight of them, as we do not have enough data about consumption for these distributors before the VAT reform. These distributors are also small ones.

${ }^{6}$ The green quota refers to a contribution for the production of renewable energy, which firms pass to consumers. Firms are obliged to purchase a minimum amount of green certificates to support the development of renewable energy sources.
} 
The summary statistics reveal a significant drop in the electricity price over the period of the temporary VAT cut at $6 \%$. However, the costs of the different components may also have changed over that period, sometimes under the influence of different policy changes. To identify the impact of the VAT change on prices, we should carefully consider the counterfactual evolution of electricity prices in the absence of the VAT change. We will do that using the change of the price for firms as a counterfactual.

Turning to consumption data, they are provided by Synergrid, the Belgian federation of network operators. The consumption data consists of the monthly amount of kWh flowed over the electricity grid through each network operator. This measure does not account for the electricity consumed by households producing their own electricity (e.g., through solar panels). Although the auto production of electricity is becoming increasingly popular in Belgium (due to generous subsidy schemes ${ }^{7}$ ), the vast majority of electricity consumed by Belgian households is observable since it flows over the grid. Our data can distinguish electricity consumption for different consumption profiles. For household consumption, we use the data of households having a ratio of night/day usage equal to $1,3{ }^{8}$ This consumption profile tends to have a yearly consumption close to $3,500 \mathrm{kWh}$, which corresponds to the price series we consider. These data also allow us to separate the consumption of households benefiting from social tariffs. A distinction that is important as these households face different prices.

Table 2

\section{Summary Statistics - Electricity Consumption}

\begin{tabular}{lccc}
\hline \hline Variable & $\begin{array}{c}21 \% \text { VAT period } \\
(01 / 13-03 / 14)\end{array}$ & $\begin{array}{c}\text { 6\% VAT period } \\
(04 / 14-08 / 15)\end{array}$ & $\begin{array}{c}21 \% \text { VAT period } \\
(09 / 15-12 / 16)\end{array}$ \\
\hline $\begin{array}{l}\text { Consumption } \\
\text { (kWh) }\end{array}$ & 267.81 & 255.90 & 245.39 \\
$\begin{array}{l}\text { Auto production } \\
\text { (TWh) }\end{array}$ & 1.46 & 1.80 & 1.75 \\
Sunlight & 122.42 & 122.19 & 156.33 \\
Degree-day & 224.20 & 188.29 & 142.94 \\
\hline \hline
\end{tabular}

Notes: Consumption is the average monthly consumption per EAN code in $\mathrm{kWh}$. The hours of sunlight and degreeday are the monthly average over the mentioned period. Auto production is a yearly estimate at the national level and is expressed in $T W h$.

\footnotetext{
${ }^{7}$ See Boccard \& Gautier (2020) and Gautier \& Jacqmin (2020) on the impact of subsidies for solar panels on PV installations in the Belgian region of Wallonia.

${ }^{8}$ This correspond to the Synthetic Load Profile S21 provided by Synergrid.
} 
Electricity consumption is highly seasonal, with picks during the winter period. The challenge of estimating the impact of the VAT reform on electricity consumption is to isolate the effect of the tax change from other events that might have occurred over the same period. For this reason, we also collect data about other factors that could have affected the evolution of electricity demand. These include the hours of sunlight, the degree-day, ${ }^{9}$ and the amount of electricity that is auto produced (i.e., the electricity not flowing over the grid). Table 2 above shows an overall decrease in electricity consumption over time. However, various factors affecting electricity demand did vary as well over the same period. The degree-day tends to decrease over the three periods, meaning that there was less need for energy to heat buildings given the higher outside temperature. The level of sunlight increased during the last period. This probably signal that less electricity for house lighting was needed. The level of auto production of electricity increases from 2014, which could partially explain the decrease in consumption flows in the network grid over the last two periods.

\section{Empirical Strategy}

We estimate the impact of the temporary VAT reform on both the price and demand for electricity. The pass-through of this VAT change on the Belgian electricity price is calculated through a difference-in-differences analysis. While we estimate the impact on demand by means of an event study regression, where we control for other possible factors affecting the electricity use over the same period. To assess the VAT incidence on residential electricity prices, we use as a control group the price of electricity paid by firms. Hence, we use the electricity price for firms as the counterfactual for the evolution of the electricity price for the household if the VAT reform was not implemented. The reason is that households are subject to the VAT but not the firms (who can recover the VAT).

The electricity price for firms is a reliable control group for this analysis. The two groups share the same cost components and are mostly provided by the same electricity providers. The main difference in the final price per kWh is the VAT paid by households. Figure 3 shows the evolution of the electricity price for both firms and households. The graph suggests that both treated (household) and control (firms) have a parallel trend both before and after the VAT cut, apart for the two periods of VAT change. Therefore, this indicates that the electricity price of

\footnotetext{
${ }^{9}$ The degree-day is a measure of the amount of energy needed during a day to heat an average building. This data is also taken from Synergrid.
} 
firms is a reliable control group for the price households would have faced in the absence of VAT change.

Although household and firm tariffs mostly share the same cost components, the same cost shock may not be passed through equally. This is because household tariffs are subject to VAT, while firm tariffs are not. Therefore, any cost shock may be passed through to household prices more than to firm prices. For instance, a $1 €$ cent $/ \mathrm{kWh}$ increase in the cost of producing energy is likely to increase firm prices by $1 €$ cent $/ \mathrm{kWh}$, while household prices should rise by 1 $€$ cent/kWh plus VAT (with $21 \%$ VAT this is $1.21 €$ cent $/ \mathrm{kWh}$ ).

This difference in cost shifting is displayed in Figure 2 below. The figure shows how the same increase in marginal cost is shifted to prices with and without VAT under imperfect competition. The left-figure shows the increase in the electricity price from $p$ to $p$ ' for firms (not subject to VAT) following a marginal cost increase from c to c'. The right-figure instead shows how the same cost shock affects the equilibrium price for households (subject to VAT). The difference in cost shifting is because the VAT reduces both the marginal (MR) and average (AR) revenues of electricity suppliers. Hence, leading to a lower quantity and a higher price after the cost increase.

Figure 2: Cost pass-through with VAT

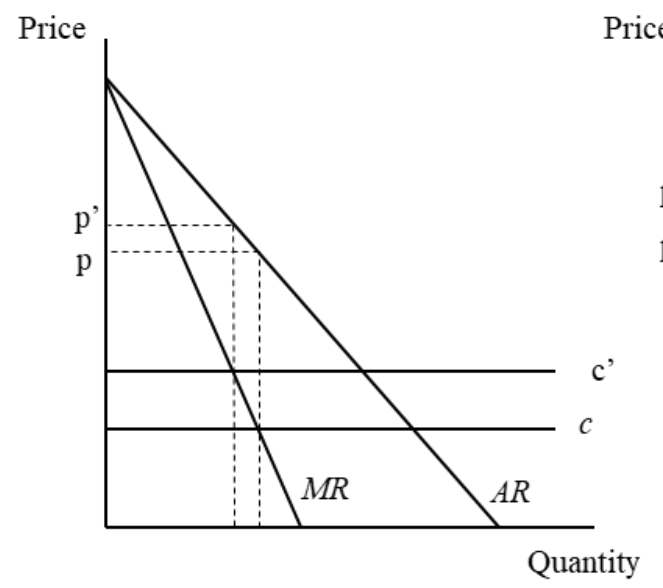

Firm group: no VAT

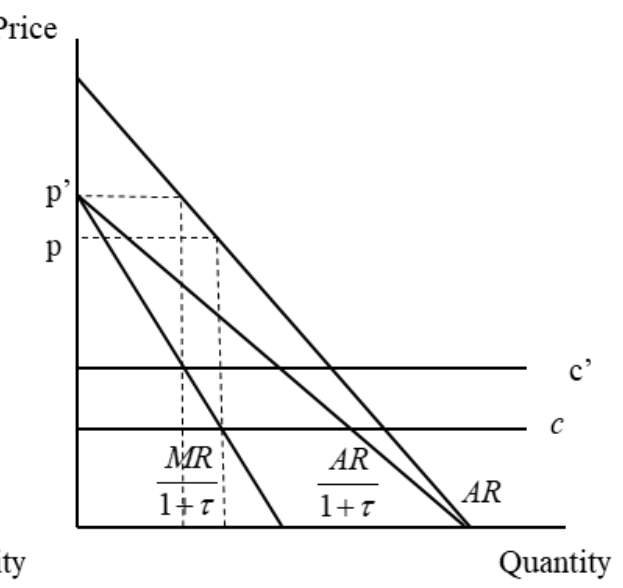

Household group :VAT

We adjust our control group to account for this asymmetry in cost shifting by including the VAT to the electricity price for firms. As this is the counterfactual scenario for household prices in the absence of VAT change, we added a $21 \%$ VAT (equal to the tax rate before the tax change) to firm prices for the entire period. In such a way, the control group is the electricity price for firms assuming they were subject to the pre-reform VAT rate of $21 \%$. This price series is displayed in figure 3 below. 
The period of analysis for the VAT pass-through goes from June 2013 to March 2016. The VAT cut from 21\% to 6\% occurs in April 2014, and it was then repealed in September 2015. The use of the electricity price for firms as the counterfactual scenario relies on the fundamental assumption that nothing else apart from the temporary VAT cut affected the price of electricity differently across these two groups. Given that the period of the analysis is quite narrow, it is easy to check that no other major policy changes can have affected the price of electricity in Belgium.

Another critical assumption is that the VAT cut only affected the household price. Hence, it did not have an impact on the price of electricity paid by firms (no spillover effect). This assumption seems quite realistic as these two types of electricity services are not substitutable, given that households cannot subscribe to a business tariff. An increase in the household price cannot lead households to switch to a business contract, thereby increasing the electricity price for firms due to higher demand. Furthermore, Figure 3 suggests that the electricity price for firms did not vary significantly around the period of policy change.

Figure 3

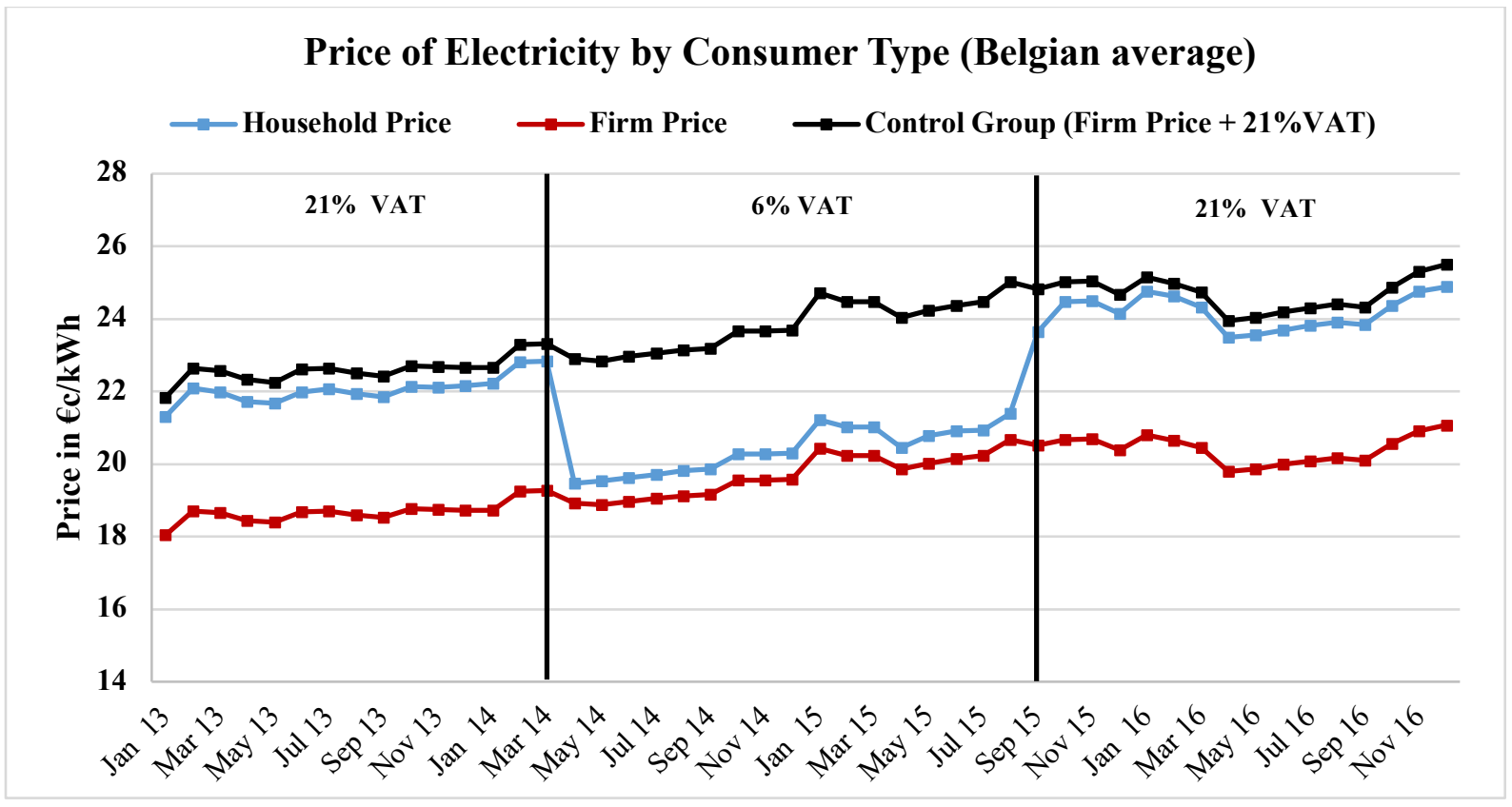

Data source: Authors with price data from the CREG.

Figure 4 below shows the evolution of the average electricity consumption of Belgian households during the period 2013-2016. ${ }^{10}$ From this graph, we can see that electricity consumption is highly seasonal, with substantial increases in use during the winter periods. The

\footnotetext{
${ }^{10}$ In the consumption analysis, we use a longer series of data compared to the price analysis to capture seasonality in electricity consumption.
} 
series in black shows the monthly evolution of electricity consumption adjusted for the seasonality in the data. The challenge of estimating the impact of the VAT reform on electricity consumption is to isolate the effect of the tax change from other events that might have occurred over the same period. We do that by running an event study regression controlling for seasonality and other determinants of electricity consumption. We do not perform a differencein-differences as for the price analysis since we do not have a reliable control group for consumption. Indeed, business electricity consumption is much higher and follows different trends than household consumption.

Figure 4

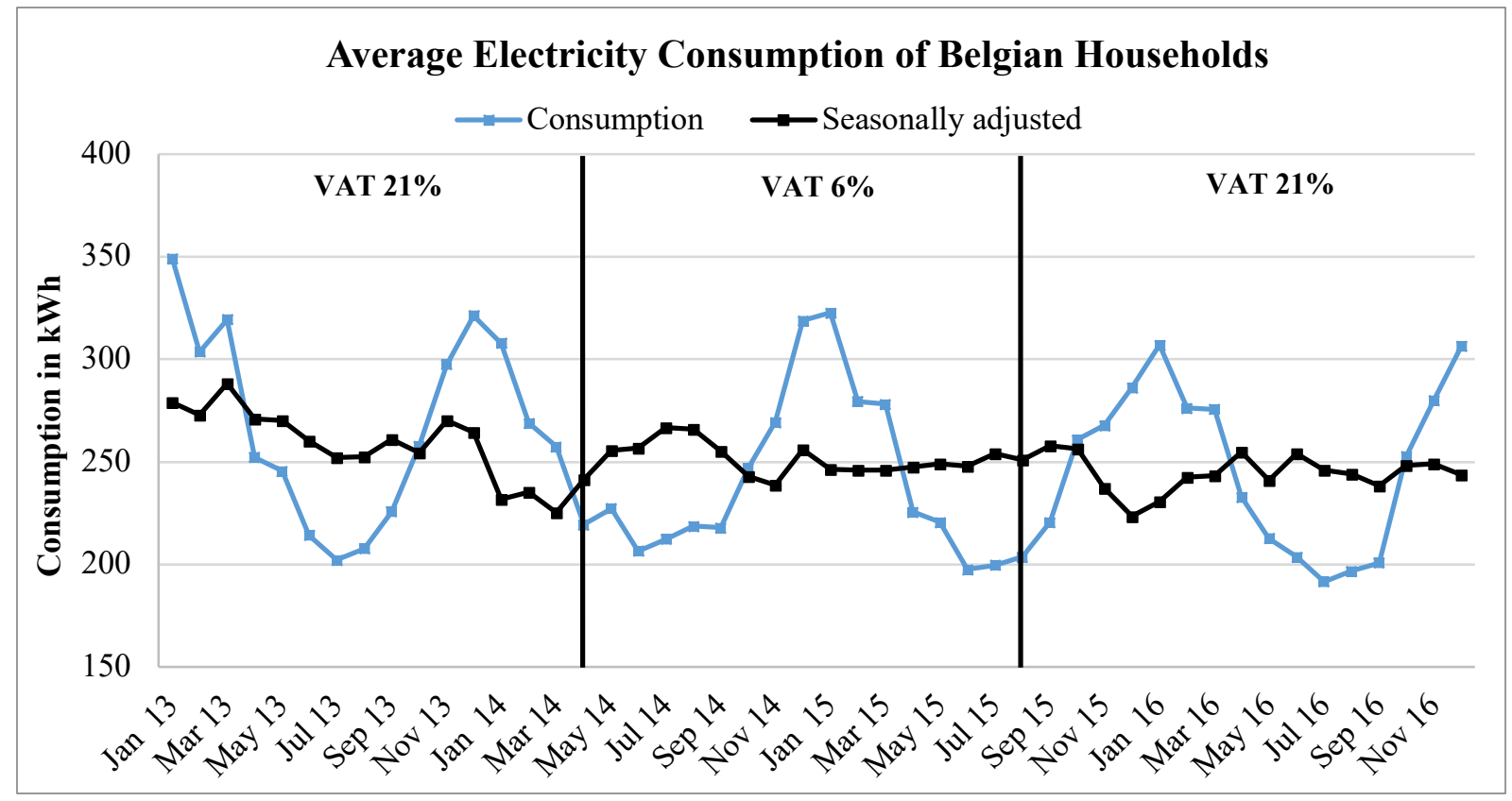

Data source: Authors, with data from Synergrid. Consumption in $\mathrm{kWh}$ is the average across households. Seasonality is computed as the monthly deviation from the average consumption in Belgium over the period.

The analysis is structured as follows. In the first part, we estimate the VAT pass-through. This analysis is done on both the total electricity price and each price component of the electricity bill. As transmission and distribution have regulated prices, we estimate the pass-through for the price components that are in competitive markets (i.e., the service provider downstream and the electricity producer upstream). We then also test for possible asymmetries in the tax shifting. In the second part, we study the impact of the VAT reform on electricity consumption. The fact that this policy change was exogenous to the consumer demand provides us with the opportunity to estimate the price elasticity of electricity demand. Since consumers experienced a substantial decrease in price and then a similar price increase, we also test for some possible asymmetries in the demand response to these opposite price variations. 


\subsubsection{VAT Pass-Through to Total Electricity Price}

We estimate the impact of the temporary VAT cut on the total price of electricity in Belgium by means of a difference-in-differences regression. We use the total price of electricity paid by professional consumers as a control group during the period of the temporary tax change. The model is specified as follows:

$$
L N(P)_{i j t}=\beta_{0}+\beta_{1} H H_{j}+\beta_{2} V A T_{c u t}+\beta_{3} L N(1+\tau)_{t}+\varepsilon_{i j t}
$$

Where $L N(P)_{i j t}$ is the natural $\log$ of the (VAT inclusive) electricity price of provider $i$ for consumer profile $j$ in month $t$. The consumer profiles $j$ are either households or enterprises. $\beta_{0}$ is the intercept of the model and measures the average (VAT inclusive) price for firms (control group). The variable $H H_{j}$ is a dummy equal to 1 if the price concerns a household tariff and 0 otherwise. Its coefficient $\beta_{1}$ captures the average difference between the firm price and the household price. $V A T_{c u t}$ is a dummy variable equal to 1 during the period of the temporary VAT cut and 0 otherwise. That is, from April 2014 until August 2015. Its coefficient $\beta_{2}$ measures the evolution of the electricity price for firms during this period, which is the counterfactual scenario for household prices. As the dependent variable is expressed in logarithmic terms, this coefficient measures the percentage change in the electricity price for firms during the period of the VAT reduction.

$L N(1+\tau)_{t}$ is the natural $\log$ of the VAT multiplicator, where $\tau$ is the current VAT rate in month $t$. (i.e. either 0.06 or 0.21 ) The coefficient $\beta_{3}$ can be interpreted as the difference-indifferences estimator of the VAT pass-through rate. This coefficient measures the pass-through rate of the temporary VAT reform by considering the evolution of the electricity price for firms as the counterfactual scenario. More specifically, the VAT pass-through rate can be defined as follows:

$$
\beta_{3}=\frac{\partial L N(P)}{\partial L N(1+\tau)}=\frac{\Delta P / P}{\Delta \tau /(1+\tau)}
$$

The model is estimated for the period going from June 2013 until March 2016. Table 3 below shows the OLS estimates for the parameters of the difference-in-differences regression outlined in equation (1). From these estimates, we can infer the causal impact of the temporary VAT change on electricity prices. The coefficient $\beta_{1}$ shows that household prices are slightly lower than firm prices, including VAT (control group). The coefficient $\beta_{2}$ measures the percentage change in the price of the control group during the period of the temporary VAT cut. Its estimate 
indicates that firm prices (including VAT) increased by $1 \%$ during this period. ${ }^{11}$ This means that in case the VAT cut was not implemented, the household prices would have increased by the same amount. The coefficient $\beta_{3}$ indicates the pass-through rate of the temporary VAT reform. The estimation suggests that the temporary VAT change was entirely shifted to electricity prices, with a pass-through rate equal to $100 \%$.

Table 3

\section{Impact of VAT Reform on Total Electricity Price}

\begin{tabular}{lcc}
\hline \hline Variable & Simple Difference & Diff-in-Diffs \\
\hline \hline Intercept $\left(\boldsymbol{\beta}_{\mathbf{0}}\right)$ & $2.95^{* * *}$ & $2.96^{* * *}$ \\
& $(0.01)$ & $(0.01)$ \\
Household Tariff $\left(\boldsymbol{\beta}_{\mathbf{1}}\right)$ & & $-0.02^{* * *}$ \\
& & $(0.04)$ \\
VAT Cut $\left(\boldsymbol{\beta}_{\mathbf{2}}\right)$ & & $0.01^{* * *}$ \\
& $0.93^{* * *}$ & $(0.08)$ \\
VAT Reform $\left(\boldsymbol{\beta}_{\mathbf{3}}\right)$ & $(0.03)$ & $1.00^{* * *}$ \\
\hline Pass-through Rate & $\mathbf{9 3 \%}$ & $(0.04)$ \\
C.I. & {$[0.88-0.98]$} & $\mathbf{1 0 0 \%}$ \\
\hline \hline $\boldsymbol{R}^{\mathbf{2}}$ & 0.27 & {$[0.93-1.08]$} \\
\hline \hline
\end{tabular}

Notes: *, ** and *** indicate statistical significance at the 0.10, 0.05 and 0.01 level respectively. Standard errors are in parenthesis. There are 6,256 observations in both model specifications.

We also re-run regression (1) to check whether the perfect shifting conceals some heterogeneity in tax shifting across different service providers and contract types. However, we do not find any shifting heterogeneity across providers and contracts. Hence, confirming the result of perfect tax shifting of the VAT change on electricity prices. Table 3 also shows the result of a simple difference estimator for the VAT pass-through. As we can see from the results, controlling for the change in business price affects the results. With a simple difference estimator, we would have concluded wrongly that the VAT was slightly (but significantly) under shifted.

The total electricity price is the sum of different price components. Two of these components have regulated prices as they are provided by network operators that are local monopolies. These are the prices for the distribution and transmission of electricity. Given that the energy

\footnotetext{
${ }^{11}$ As we specified the model in log terms, we do not find much difference if we adjust or not the control group with the VAT rate. Yet, this delivers different results when estimating tax shifting in absolute terms.
} 
regulator regulates these prices, network operators cannot respond freely to the VAT change. As a result, the VAT cut must have been entirely shifted. Service providers, however, are in a competitive market environment. They can choose how to shift the tax change on the price of the electricity that they provide. In particular, service providers charge to consumers the cost of the energy supplied and the green quota for renewable energy. The VAT may have been shifted differently on these two price components.

Therefore, we re-run equation (1) to estimate the VAT pass-through for these two components separately. The results are displayed in Table 4 below. Service providers have fully shifted the VAT to the cost of energy with a pass-through rate of $102 \%$. The impact of the VAT on the green quota is instead noisier, as the share of this component on the electricity bill is the smallest in magnitude. We estimate an average pass-through of $109 \%$, which is not statistically significant. Therefore, non-regulated suppliers in the electricity market have reacted similarly to those that are not regulated (i.e., the DSOs).

Table 4

\section{Impact of VAT Reform on Electricity Price Components}

\begin{tabular}{lcc}
\hline \hline Variable & Energy & Green Quota \\
\hline \hline Intercept $\left(\boldsymbol{\beta}_{\mathbf{0}}\right)$ & $1.82^{* * * *}$ & 0.00 \\
& $(0.06)$ & $(0.20)$ \\
HH Tariff $\left(\boldsymbol{\beta}_{\mathbf{1}}\right)$ & $-0.06^{* *}$ & 0.00 \\
& $(0.03)$ & $(0.08)$ \\
$\mathbf{V A T}_{\text {cut }}\left(\boldsymbol{\beta}_{\mathbf{2}}\right)$ & 0.02 & 0.02 \\
\multirow{2}{*}{$\mathbf{V A T}_{\text {pass-through }}\left(\boldsymbol{\beta}_{\mathbf{3}}\right)$} & $(0.01)$ & $(0.08)$ \\
\hline \multirow{2}{*}{$\boldsymbol{R}^{2}$} & $\mathbf{1 . 0 2 * * * *}$ & $\mathbf{1 . 0 9}$ \\
& $(0.25)$ & $(0.83)$ \\
\hline \hline
\end{tabular}

Notes: $*, * *$ and $* * *$ indicate statistical significance at the 0.10, 0.05 and 0.01 level respectively. Standard errors, clustered at the distributor level, are in parenthesis. The first model specification 'Energy' has 272 observations, while the second 'Green Quota' has 817 observations. This is because the energy cost is homogeneous across regions, while green quota can vary regionally.

\subsubsection{Symmetry in VAT pass-through}

The temporary VAT reform provides an opportunity to test for asymmetries between the shifting of the tax cut and the consecutive tax hike. Although the results above suggest a full shifting of the VAT reform, we check whether this finding still holds when studying the two events separately. That is, we would like to test whether the VAT cut in April 2014 and the 
successive VAT hike in September 2015 were both perfectly shifted to electricity prices. To test for this hypothesis, we estimate a difference-in-differences regression where the two VAT reforms are considered separately. The model estimated is as follows:

$$
\begin{aligned}
L N(P)_{i j t}=\beta_{0}+\beta_{1} H H_{j}+\beta_{2} V A T_{c u t}+\beta_{3} L N & (1+\tau)_{t}+ \\
& \\
& +\beta_{4} V A T_{\text {hike }}+\beta_{5}\left(V A T_{\text {hike }} * H H_{j}\right)+\varepsilon_{i j t} .
\end{aligned}
$$

Regression (2) is similar to regression (1). $L N(P)_{i j t}$ is the natural log of electricity price of provider $i$ for consumer profile $j$ in month $t . \beta_{0}$ is the average price in the control group during the period before the temporary VAT reform. While $\beta_{1}$ measures the difference between this price and the average household price during the same period. The interpretation of $\beta_{2}$ and $\beta_{3}$ are the same as in regression (2), with the only difference that the baseline period here is only the one before the VAT cut (June 2013 - March 2014). ${ }^{12}$ The $V A T_{\text {hike }}$ is a dummy variable equal to 1 for the period after the VAT hike. Its coefficient $\beta_{4}$ indicate the percentage price difference in the control group from the period before the VAT reform and the period after the VAT reinstatement at $21 \%$. This would be the counterfactual scenario for household prices if the VAT change did not occur.

Table 5

\section{Test for Asymmetries in VAT Pass-Through}

\begin{tabular}{lccc}
\hline Variable & Total & Energy & $\begin{array}{c}\text { Green } \\
\text { Quota }\end{array}$ \\
\hline \hline $\operatorname{VAT}_{\text {cut }}\left(\boldsymbol{\beta}_{\mathbf{2}}\right)$ & $0.05^{* * *}$ & 0.00 & 0.14 \\
$\mathbf{V A T}_{\text {pass-through }}\left(\boldsymbol{\beta}_{\mathbf{3}}\right)$ & $(0.00)$ & $(0.03)$ & $(0.09)$ \\
& $0.99^{* * *}$ & $1.02^{* * *}$ & 1.07 \\
$\mathbf{V A T}_{\text {hike }}\left(\boldsymbol{\beta}_{\mathbf{4}}\right)$ & $(0.04)$ & $(0.12)$ & $(0.96)$ \\
& $0.04^{* * *}$ & $-0.10^{* * *}$ & 0.14 \\
$\mathbf{H H}$ Tariff * $\mathbf{V A T}_{\text {hike }}\left(\boldsymbol{\beta}_{\mathbf{5}}\right)$ & $(0.00)$ & $(0.04)$ & $(0.10)$ \\
\hline \hline $\boldsymbol{R}^{\mathbf{2}}$ & 0.00 & -0.00 & 0.01 \\
\hline \hline
\end{tabular}

Notes: *,** and *** indicate statistical significance at the 0.10, 0.05 and 0.01 level respectively. Standard error, clustered at the distributor level, are in parenthesis.

The coefficient $\beta_{5}$ is the difference-in-differences estimator of the VAT reinstatement at $21 \%$ on household electricity prices. Given that we are using the time before the temporary VAT

\footnotetext{
${ }^{12}$ In regression (2) the baseline period was the period outside the VAT cut: before April 2014 and after September 2015.
} 
reform as the baseline period, $\beta_{5}$ is testing whether household electricity prices revert to its initial before the reform. If that is the case, the coefficient $\beta_{5}$ should be equal to zero as this means that after the VAT reinstatement at $21 \%$, household electricity prices reverted to their initial level (controlling for the evolution of firms prices). The results displayed in Table 5 above suggest that the impact of the two VAT changes on electricity prices was symmetric and that both tax changes were entirely shifted. The pass-through of the VAT cut on the total electricity price is equal to $99 \%$, while that of the energy components is $102 \%$. Again, the passthrough for the green quota is $107 \%$, but it is not statistically significant.

\subsubsection{The Impact of the VAT Reform on Electricity Demand}

We study the impact of the VAT reform on electricity consumption by measuring the change in electricity demand during the policy change while controlling for other confounding factors. The period of study is four years, from January 2013 to December 2016. During this period, we first observe a VAT decrease from 21\% to 6\% in April 2014 and then a VAT reinstatement at $21 \%$ in September 2015. Therefore, the aim is to estimate the percentage change in electricity demand following these two events. More specifically, we run the following regression.

$$
L N(C)_{j t}=D_{j}+M_{t}+\beta_{C} V A T_{t>c u t}+\beta_{H} V A T_{t>h i k e}+\sum_{n} \theta_{n} X_{n j t}+\varepsilon_{j t} .
$$

Where $L N(C)_{j t}$ is the natural log of the (average) electricity consumption (measured in $\mathrm{kWh}$ per capita) in the area supplied by distributor $j$ during month $t . D_{j}$ is the distributor fixed effect, which measures the average consumption level in the area supplied by distributor $j . M_{t}$ is the month fixed effect that captures seasonality at the monthly level. The variable $V A T_{t>c u t}$ is a dummy variable equal to 1 if the monthly observation is during or after the first VAT change occurred in April 2014. Its coefficient $\beta_{C}$ measures the percentage change in electricity demand after the VAT cut. The variable $V A T_{t>\text { hike }}$ is a dummy variable equal to 1 if the monthly observation is during or after the VAT hike in September 2015. Its coefficient $\beta_{H}$ captures the percentage change in electricity demand after the VAT hike. The baseline period is the one before the first VAT reform. Hence, if the two effects cancel out (i.e., symmetric response), we would observe that $\beta_{C}+\beta_{H}=0$. Lastly, $X_{n}$ is the set of control variables included in the regression that can vary both at the distributor and monthly level. These variables include the amount of electricity auto produced by households, the degree-day (Degrés-jours Synergrid), and the hours of sunlight during that month. We also include the electricity price net of VAT, so that we can control for other price changes not related to the VAT reform. 
We run this regression for both standard and social tariffs. Social tariffs are homogenous across the country and are entirely subject to regulation. Yet, they are also subject to VAT, and hence they have been impacted by the temporary VAT reform (VAT change was entirely shifted on social tariffs). These tariffs are entitled to low-income households under a specific set of legal conditions. As we can identify the electricity consumption subject to these tariffs, we can estimate the demand response of poorer households, and compare it to the one of the rest of the population. The results of regression (3) are shown in Table 6 below. Regression (3) measures the change in demand relative to the baseline demand before the VAT change (January 2013 March 2014). Columns (1) \& (2) and (5) \& (6) of Table 6 also show the result of a different version of regression (3), where we measure the change in electricity demand by using as baseline period the one before (January 2013 - March 2014) and after (September 2015 December 2016) the VAT cut, where the VAT was at $21 \%$.

Table 6

\section{Impact of VAT reform on demand}

\begin{tabular}{lccccccccc}
\hline \hline & \multicolumn{3}{c}{ Standard Tariffs (1-4) } & \multicolumn{5}{c}{ Social Tariffs (5-8) } \\
\hline \hline Variable & $\mathbf{( 1 )}$ & $\mathbf{( 2 )}$ & $\mathbf{( 3 )}$ & $\mathbf{( 4 )}$ & $\mathbf{( 5 )}$ & $\mathbf{( 6 )}$ & $\mathbf{( 7 )}$ & $\mathbf{( 8 )}$ \\
\hline \hline \multirow{2}{*}{ VAT cut $\left(\beta_{C}\right)$} & $\mathbf{2 . 1 2}$ & $\mathbf{2 . 0 5}$ & $\mathbf{2 . 0 6}$ & $\mathbf{2 . 0 7}$ & $\mathbf{1 . 9 9}$ & $\mathbf{1 . 8 1}$ & $\mathbf{2 . 5 9}$ & $\mathbf{2 . 4 8}$ \\
& $(0.20)$ & $(0.20)$ & $(0.41)$ & $(0.40)$ & $(0.22)$ & $(0.23)$ & $(0.49)$ & $(0.49)$ \\
VAT hike $\left(\beta_{H}\right)$ & & & $\mathbf{- 2 . 1 4}$ & $\mathbf{- 2 . 0 5}$ & & & $\mathbf{- 2 . 0 8}$ & $\mathbf{- 1 . 6 0}$ \\
& & & $(0.23)$ & $(0.24)$ & & & $(0.27)$ & $(0.28)$ \\
Degree-Day & 0.56 & 0.57 & 0.56 & 0.57 & 0.56 & 0.59 & 0.54 & 0.58 \\
& $(0.02)$ & $(0.02)$ & $(0.02)$ & $(0.02)$ & $(0.02)$ & $(0.02)$ & $(0.02)$ & $(0.02)$ \\
Sunlight & -0.49 & -0.48 & -0.49 & -0.48 & -0.47 & -0.44 & -0.44 & -0.44 \\
Auto & $(0.03)$ & $(0.03)$ & $(0.03)$ & $(0.03)$ & $(0.04)$ & $(0.04)$ & $(0.04)$ & $(0.04)$ \\
production & -1.59 & -1.50 & -1.57 & -1.51 & -0.77 & -0.72 & -0.98 & -0.93 \\
Price (no VAT) & $(0.05)$ & $(0.07)$ & $(0.12)$ & $(0.12)$ & $(0.07)$ & $(0.07)$ & $(0.16)$ & $(0.16)$ \\
& & -0.04 & & -0.04 & & 0.34 & & 0.35 \\
\hline \hline
\end{tabular}

Notes: Standard errors, clustered at the distributor level, are in parenthesis. All coefficients are statistically significant at the 0.01 level, except the one on price (net of VAT) in columns (2) and (4). All models have 720 observations and include interactions between the distributor and monthly FEs (seasonal effect at the distributor level). Their R-squared is around 99\%. Without including such interactions, results are very similar, but the Rsquared drop to $97 \%$. The dummy variables VAT cut and VAT hike are rescaled (divided by 100) so that they can present the coefficients in percentage points.

From column (1) to column (4) of Table 6, we show the estimated coefficients for households subject to standard tariffs, which account for the majority of electricity consumption. The first two columns show that during the period of the VAT cut at $6 \%$, electricity demand was around 
$2 \%$ larger than the period when the VAT as at $21 \%$. This suggests that the VAT reduction has increased electricity demand. Columns 3 and 4 display a similar result by separating the demand response to the VAT cut and the successive VAT hike. The demand response to the two VAT changes looks very symmetric. Households first increased their demand by $2 \%$ when the VAT was reduced at $6 \%$ and then decreased their demand to the same extent when the VAT was reinstated at $21 \%$. As a result, after the VAT reinstatement, their demand reverts to the level before the VAT cut (controlling for climate variables and auto production level). Thus, for the same price change, but of a different sign, we get a symmetric change in demand.

Columns (5) to (8) of Table 6, display the estimated coefficients for households subject to social tariffs. They account for a minority of the electricity demand, which is composed of low-income households mostly. Results are similar to those of other households, with their change in electricity demand close to $2 \%$. Yet, the last two columns show that demand increased by more than $2 \%$ during the VAT cut, while it dropped by less than $2 \%$ after the VAT reinstatement. However, after January 2016, social tariffs were reduced by the energy authority (partly to protect the low-income group from the VAT reinstatement). This social tariff adjustment can explain why demand did not revert to the level before the VAT cut. Nevertheless, including the price net of VAT as a control variable, does not account for this effect (its coefficient is even positive). ${ }^{13}$

The coefficients for the control variables included in regression (3) have all the expected signs. The degree-day measures how much heating is needed over a given month as a function of the outside temperature. The sign of its coefficient is positive and significant, which means that electricity consumption increases when more heating is needed. The coefficient for the monthly hours of sunlight is instead negative and significant. This indicates that more hours of sunlight leads to lower electricity consumption, which is possibly due to reduced home lighting. Lastly, the auto production of electricity tends to reduce electricity consumption from the grid. This result is also quite intuitive as these two sources of energy are substitutes. Most of the auto production of electricity in Belgium is through solar panels, which allows households to consume their own energy instead of getting it from the electricity grid.

\footnotetext{
${ }^{13}$ Social tariffs are fully regulated and the only two sources of variation over the sample period are the VAT change (mainly) and the update in January 2016. Thus, the positive coefficient for the price net of VAT should not be indicative, as it could be due to the little variation in the price data and its correlation with some unobserved factor after January 2016.
} 


\subsubsection{The Price Elasticity of Electricity Demand}

The exogenous variation in electricity prices due to the VAT reform allows us to estimate the price elasticity of electricity demand. The estimates can be easily retrieved from regression (3), as we know the change of both price and demand after the VAT reform. However, the VAT reform was the principal but not the only source of price variation in the data. Changes in electricity prices over the sample period also occur due to updates in regulated components, such as transmission and distributions, and due to some other shocks to energy prices. As we can disentangle the type of price variations, we can estimate the demand elasticity by exploiting different sources of changes in price.

The change in price due to the VAT change is very likely to be exogenous to household demand because both reforms were implemented for reasons outside the electricity market. This constitutes a good source of price variation to identify the demand elasticity. Another source of price variation is the change in regulated price components. The energy regulator sets prices for transmission and distribution of electricity, which change at least once per year. Over the sample period, they steadily increased. These prices should be cost-based and not related to changes in demand-side conditions. For this reason, they can also constitute a useful source of price variation to identify the demand elasticity. The residual variation in electricity prices is due to changes in the cost of energy, which is not regulated. These price changes can be due to temporal or permanent cost shocks in producing and selling electricity to residential consumers. Nevertheless, they can also be related to changes in demand-side conditions, as service providers are free to set their prices. In such a case, price changes are not fully exogenous to household demand and can, therefore, constitute a spurious source of price variation.

We estimate the demand elasticity by exploiting these different sources of price variation. In particular, we identify the demand elasticity by using either: i) the VAT change; ii) the VAT change plus the regulated price change; or iii) all price changes. We do this exercise for both standard and social tariffs. ${ }^{14}$ More specifically, we estimate the demand elasticity by running the following regression:

$$
L N(C)_{j t}=D_{j}+M_{t}+\beta L N(\text { Price })_{t}+\sum_{n} \theta_{n} X_{n j t}+\varepsilon_{j t} .
$$

This regression is mainly similar to regression (3) except that the VAT dummies are replaced directly by the price variable $L N(\text { Price })_{t}$. The price variable is either: i) the log of the VAT

\footnotetext{
${ }^{14}$ However, as social tariffs are fully regulated, estimating the demand elasticity using the VAT change and the regulated price component is equivalent to exploiting all price variation in the data.
} 
rate, $L N(1+\tau)_{t}$, when we exploit the VAT change only; ii) the log of the regulated price (VAT included); or iii) the total electricity price. The coefficient $\beta$ is the price elasticity of electricity demand. We estimate regression (4) by standard OLS procedure. Moreover, we also estimate the first two specifications through a two-stage least square (2SLS) procedure. Where in the first stage, we instrument the price by either a dummy variable for the VAT cut or by the regulated price (net of VAT) plus the VAT dummy. The results of this analysis are displayed in Table 7 below.

Table 7

\section{Demand Elasticity}

\begin{tabular}{|c|c|c|c|c|c|c|c|c|}
\hline \multirow[b]{3}{*}{ Variable } & \multicolumn{5}{|c|}{ Standard tariffs $(1-5)$} & \multicolumn{3}{|c|}{ Social tariffs $(6-8)$} \\
\hline & \multicolumn{2}{|c|}{ VAT only } & \multicolumn{2}{|c|}{$\begin{array}{l}\text { VAT and } \\
\text { regulated price }\end{array}$} & \multirow{2}{*}{$\begin{array}{c}\begin{array}{c}\text { Full } \\
\text { price }\end{array} \\
\begin{array}{c}\text { OLS } \\
\text { (5) }\end{array}\end{array}$} & \multicolumn{2}{|c|}{ VAT only } & \multirow{2}{*}{$\begin{array}{c}\begin{array}{c}\text { Full } \\
\text { price }\end{array} \\
\begin{array}{c}\text { OLS } \\
\text { (8) }\end{array}\end{array}$} \\
\hline & $\begin{array}{c}\text { OLS } \\
\text { (1) }\end{array}$ & $\begin{array}{l}\text { 2SLS } \\
(2)\end{array}$ & $\begin{array}{l}\text { OLS } \\
(3)\end{array}$ & $\begin{array}{l}\text { 2SLS } \\
\text { (4) }\end{array}$ & & $\begin{array}{l}\text { OLS } \\
(6)\end{array}$ & $\begin{array}{l}\text { 2SLS } \\
\text { (7) }\end{array}$ & \\
\hline LN(price) & $\begin{array}{l}\mathbf{- 0 . 1 6} \\
(0.01)\end{array}$ & $\begin{array}{l}\mathbf{- 0 . 1 7} \\
(0.03)\end{array}$ & $\begin{array}{l}\mathbf{- 0 . 0 9} \\
(0.01)\end{array}$ & $\begin{array}{l}\mathbf{- 0 . 1 0} \\
(0.01)\end{array}$ & $\begin{array}{l}\mathbf{- 0 . 1 2} \\
(0.02)\end{array}$ & $\begin{array}{l}\mathbf{- 0 . 1 7} \\
(0.02)\end{array}$ & $\begin{array}{l}\mathbf{- 0 . 1 7} \\
(0.02)\end{array}$ & $\begin{array}{l}\mathbf{- 0 . 1 4} \\
(0.02)\end{array}$ \\
\hline $\begin{array}{l}\text { Degree- } \\
\text { Day }\end{array}$ & $\begin{array}{c}0.56 \\
(0.02)\end{array}$ & $\begin{array}{c}0.50 \\
(0.04)\end{array}$ & $\begin{array}{c}0.56 \\
(0.02)\end{array}$ & $\begin{array}{c}0.52 \\
(0.03)\end{array}$ & $\begin{array}{c}0.58 \\
(0.02)\end{array}$ & $\begin{array}{c}0.55 \\
(0.02)\end{array}$ & $\begin{array}{c}0.55 \\
(0.02)\end{array}$ & $\begin{array}{c}0.53 \\
(0.02)\end{array}$ \\
\hline Sunlight & $\begin{array}{l}-0.48 \\
(0.03)\end{array}$ & $\begin{array}{l}-0.33 \\
(0.05)\end{array}$ & $\begin{array}{l}-0.47 \\
(0.03)\end{array}$ & $\begin{array}{l}-0.30 \\
(0.03)\end{array}$ & $\begin{array}{l}-0.46 \\
(0.03)\end{array}$ & $\begin{array}{l}-0.45 \\
(0.04)\end{array}$ & $\begin{array}{l}-0.44 \\
(0.04)\end{array}$ & $\begin{array}{l}-0.45 \\
(0.04)\end{array}$ \\
\hline $\begin{array}{l}\text { Auto } \\
\text { production }\end{array}$ & $\begin{array}{l}-1.59 \\
(0.05) \\
\end{array}$ & $\begin{array}{l}-1.43 \\
(0.08) \\
\end{array}$ & $\begin{array}{l}-1.21 \\
(0.05) \\
\end{array}$ & $\begin{array}{l}-1.14 \\
(0.05) \\
\end{array}$ & $\begin{array}{l}-1.32 \\
(0.05) \\
\end{array}$ & $\begin{array}{l}-0.85 \\
(0.07) \\
\end{array}$ & $\begin{array}{l}-0.85 \\
(0.07) \\
\end{array}$ & $\begin{array}{l}-0.86 \\
(0.07) \\
\end{array}$ \\
\hline Elasticity & -0.16 & -0.17 & -0.09 & -0.10 & -0.12 & -0.17 & -0.17 & -0.14 \\
\hline C.I. & $0.13-0.19$ & $0.10-0.24$ & $0.08-0.10$ & $0.07-0.13$ & $0.10-0.15$ & $0.13-0.20$ & $0.14-0.21$ & $0.10-0.17$ \\
\hline
\end{tabular}

Notes: all coefficients are statistically significant at the 0.01 level. Standard errors, clustered at the distributor level, are in parenthesis. ). All models have 720 observations and include interactions between the distributor and monthly FEs (seasonal effect at the distributor level). Their R-squared is around 99\%. Without including such interactions, results are very similar, but the R-squared drops to $97 \%$.

The $\beta$ coefficient for price indicates the estimate for the demand elasticity. According to the different model specifications displayed in Table 7, this can range from -0.09 to -0.17 . Although these estimates seem quite low, they are nevertheless significant and in line with other studies based on quasi-experimental price variations (see Ito, 2014; Deryugina, MacKay, \& Reif, 2020). Interestingly, Table 7 highlights that (poor) households subject to social tariffs have a similar demand elasticity than other consumers. When exploiting all price variation, this is equal to -0.14 and -0.12 , respectively (see columns 5 and 8 ).

If we measure the demand elasticity using the VAT change only, we get a slightly larger demand elasticity, for both standard and social tariffs, which are equal to -0.17 . Interestingly, when 
exploiting changes in both the VAT and regulated price components, we get significantly lower demand elasticities. For standard tariffs, this decreases the demand elasticity from -0.17 to 0.10. Using OLS or 2SLS does not really affect the coefficients, but it slightly increases the range of the confidence intervals. Hence, these findings suggest that consumers are more sensitive to changes in the VAT rate than changes in other price components. Two elements could help explain such a result. First, the VAT change was announced and hotly debated in the media, which makes the price variation quite salient to consumers. Second, the change in price was easy to understand, as it mostly consisted of the difference in the VAT rate. In contrast, changes in other price components tend to be smaller and less noticeable, as they have to be carefully checked in the monthly electricity bill. ${ }^{15}$

\subsubsection{Symmetry in Demand Elasticities}

These policy changes provide us with an excellent natural experiment to test for differences in demand response to a price hike and price cut. The answer to such a question has quite relevant policy implications, as most climate change policies would imply some energy price hike. If consumers have asymmetric responses to price changes of different signs, then this must be taken into account when evaluating the impact of these policies on energy use. Moreover, evidence of the effects of exogenous price hikes on electricity demand is very limited. Table 6 has shown that households responded to the VAT cut and the VAT reinstatement symmetrically. This means that price changes of different signs have a similar but opposite effect on demand. Therefore, estimates of demand elasticities obtained by exploiting exogenous decreases in electricity price could also be indicative of the consumer response to a price hike. More formally, we measure demand elasticity by allowing it to vary across two periods: one that goes from January 2013 to December 2014; another that goes from January 2015 to December 2016. The aim is to estimate demand elasticities for the VAT cut and the subsequent VAT hike separately. Since the VAT reform was not the only source of price variation, we do not have a perfectly symmetric price variation. In particular, there is a price drop of $-11 \%$ in the first period and a price hike of $+14 \%$ for standard tariffs and $+12 \%$ for social tariffs, in the second period. Therefore, we re-estimate regression (4) using the full price variation to control for the asymmetry in price changes and compute the demand elasticity separately for the price cut and the price hike. The results are displayed in Table 8 below.

\footnotetext{
${ }^{15}$ For instance, Sexton (2015) shows that consumers enrolling in automatic bill payment programs become less price sensitive, increasing their electricity demand due to a decline in price salience.
} 
Table 8

\section{Symmetry in Demand Elasticities}

\begin{tabular}{lcc}
\hline \hline Variable & Standard Tariffs & Social Tariffs \\
\hline \hline Demand Elasticity (VAT cut) & $\mathbf{- 0 . 1 0}$ & $\mathbf{0 . 1 2}$ \\
C.I. & {$[0.08-0.13]$} & {$[0.08-0.15]$} \\
Demand Elasticity (VAT hike) & $\mathbf{- 0 . 1 0}$ & $\mathbf{- 0 . 1 2}$ \\
C.I. & {$[0.08-0.13]$} & {$[0.08-0.16]$} \\
\hline \hline
\end{tabular}

Notes: all coefficients are statistically significant at the 0.01 level. Standard errors, clustered at the distributor level, are in parenthesis. Control variables include distributor FE, monthly FE, and their interaction, as well as all other control variables included in model (4).

As already suggested in Table 6, consumers are equally sensitive to price cuts and price hikes. The demand elasticity is symmetric. However, the estimates are slightly lower than in Table 7. Again, we do not find much difference in demand elasticities across different household types. Most households have a demand elasticity of -0.10 , while for (poor) households subject to social tariffs, the elasticity is -0.12 . This result can have important implications for climate change policies, as it highlights that consumers are not only sensitive to reductions in electricity prices. They are also equally sensitive to price increases due to taxation.

\subsubsection{Regional and Time Heterogeneity}

We further investigate the extent of heterogeneity in demand elasticity across Belgian areas. We re-estimate regression (4) by allowing each Belgian region to have different demand elasticities. The results of this estimation lead us to compute the demand elasticities for the Region of Brussels, Flanders, and Wallonia. These estimates are shown in Table 9, where we use the full price variation. ${ }^{16}$ Concerning standard tariffs, households in Wallonia and Flanders display similar demand elasticities in the range of -0.13 and -0.11 . Households in the Region of Brussels display a higher demand elasticity of -0.20 , except for those subject to social tariffs who display the lowest elasticity, not significantly different from zero. Households entitled to social tariffs in Flanders and Wallonia have a demand elasticity of -0.20 and -0.10 , respectively. This evidence thus suggests that similar price changes can have a different impact on electricity demand across geographical areas and household types. Residents in the urban area of Brussels and Flemish households subject to social tariffs are the most responsive to changes in prices and hence energy taxes. In contrast, Brussels residents entitled to social tariffs do not respond to price changes significantly.

\footnotetext{
${ }^{16}$ The estimates are very similar when computing elasticities using only VAT or the VAT plus regulated price changes.
} 


\section{Regional Heterogeneity in Demand Elasticity}

\begin{tabular}{lccc}
\hline \hline & Region of Brussels & Flanders & Wallonia \\
\hline \hline Standard Tariffs & $\mathbf{- 0 . 2 0}$ & $\mathbf{- 0 . 1 3}$ & $\mathbf{- 0 . 1 1}$ \\
C.I. & {$[0.16-0.24]$} & {$[0.08-0.18]$} & {$[0.03-0.18]$} \\
Social Tariffs & $\mathbf{- 0 . 0 3}$ & $\mathbf{- 0 . 2 0}$ & $\mathbf{- 0 . 1 0}$ \\
C.I. & {$[-0.13-0.07]$} & {$[0.15-0.24]$} & {$[0.04-0.15]$} \\
\hline \hline
\end{tabular}

Notes: Demand elasticities are computed at the sample average. Estimates are obtained through the estimation of regression (4) by allowing for regional heterogeneity in demand response.

We further test for the time heterogeneity in the demand response to changes in electricity price. According to the literature, the demand response to changes in electricity prices is dynamic (Labandeira, Labeaga, \& López-Otero, 2017; Deryugina, MacKay, \& Reif, 2020). The demand elasticity tends to increase over time as consumers may take time to change their stock of appliances and their relative energy efficiency (Rapson, 2014; Sahari, 2019). Another possible explanation is that electricity prices are complex and not easily visible to consumers (Sexton, 2015). Thus, consumers may take time to realize an actual price change. In our context, the price change is likely to be more salient than a usual price change for at least two reasons. First, the VAT reforms were publicly announced in the media. Second, it was easy to assess the amount of the price change, given that it is close to the variation in the VAT rates. This means that the demand response to the VAT reform could have been faster than other price changes.

To explore the dynamics in the demand response, we estimate the variation in the $\mathrm{kWh}$ of electricity consumed during each month of VAT at $6 \%$ by taking as reference period the one with the VAT at $21 \%$. In practice, we estimate the following regression.

$$
C_{j t}=D_{j}+M_{t}+\sum_{t=-6}^{16} \beta_{t}\left(V A T_{c u t}\right)_{t}+\sum_{n} \theta_{n} X_{n j t}+\varepsilon_{j t} .
$$

Where $C_{j t}$ is the electricity consumption measured in $\mathrm{kWh}$ per capita for the area supplied by distributor $j$ during month $t$. We do not specify the dependent variable in log terms as we want to estimate the absolute change in $\mathrm{kWh}$ consumed during the period of the reform. $V A T_{\text {cut }}$ is a dummy variable equal to 1 for each month before and after the implementation of the VAT cut. We allow $t$ to be $t \in[-6,16]$, which means that we include six leads and 16 lags from the month of the VAT cut, which occurs at $t=0 .{ }^{17}$ The coefficient $\beta_{t}$ measures the increase in $\mathrm{kWh}$

\footnotetext{
${ }^{17}$ The last lag coincides with the month just before the reinstatement of the VAT at $21 \%$.
} 
consumed over each month before and after the VAT reduction at 6\%. The reference period is the one with the VAT at $21 \%$, with the exclusion of the six months pre-reform (as we need them to estimate the leads).

By including the leads up to six months before the VAT cut, we can estimate whether electricity demand increased even before the VAT was reduced. This is a useful robustness check as we know that VAT change was only announced one month before its implementation. Thus, we should not observe any effect due to the reform in those months. The lags are instead measures how the variation in electricity demand evolved over each month of VAT at $6 \%$. All other variables included in regression (5) are the same as in regression (3). The results of this analysis are displayed graphically in Figure 5 below.

Figure 5

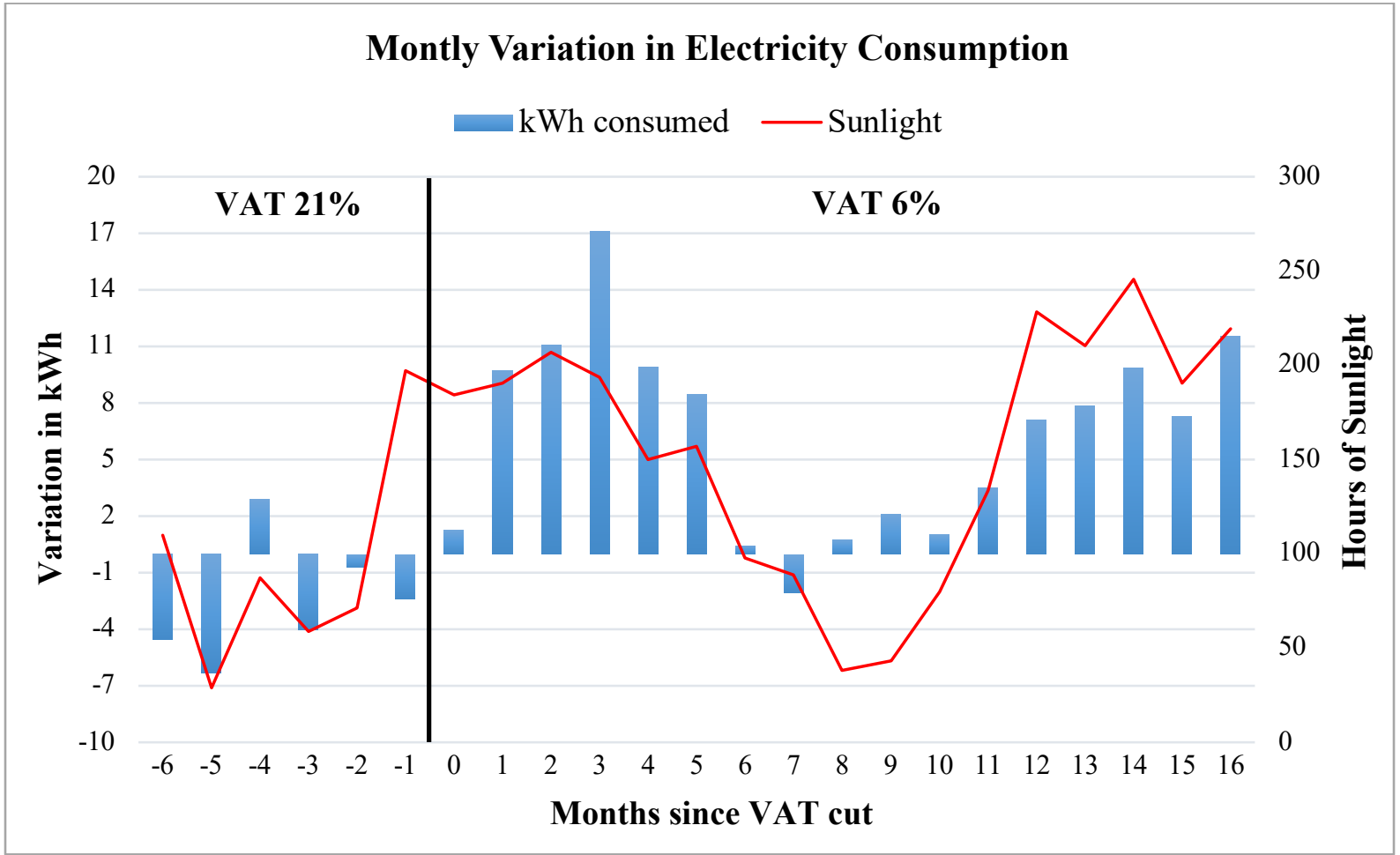

Notes: the histogram shows the estimates of each monthly $\beta_{t}$, which are the leads and lags of regression (5). The red curve displays the hours of sunlight during each month.

Figure 5 shows that electricity consumption increased almost immediately after the VAT cut, precisely one month after its implementation. The average monthly increase in electricity consumption during the period of VAT at $6 \%$ was equal to $6.30 \mathrm{kWh}$, which represents roughly a $2 \%$ increase in electricity demand. Interestingly, the demand response seems to be frontloaded, with a sharper increase during the first six months of tax reduction. This evidence suggests that consumers were well aware of the price cut and thus increased demand quickly. Subsequently, there is no significant change in electricity demand in the period that goes from 
October 2014 to February 2015, while the demand increases again in the successive months. Interestingly, Figure 5 highlights the strong correlation between the hours of sunlight and the demand response to the VAT change. Most of the demand increase occurs during months that are sunnier (and warmer). A possible reason why the electricity use did not also rise during colder and less sunny months could be because energy consumption was already high during that period. As a result, there was less scope for increasing it at the margin.

\subsubsection{Robustness Checks}

For the VAT pass-through analysis, we dispose of a reliable control group to check for the counterfactual evolution of electricity prices. We cannot adopt the same approach to study the demand response. This is because the electricity consumption of SMEs cannot be easily compared to households. SMEs consume much more electricity on average and can be affected by other unobserved factors that are less relevant for households. Nevertheless, to test the robustness of our results, we run a placebo test on the evolution of electricity consumption for SMEs. The idea is to check how the electricity consumption of SMEs varied during the period of the VAT cut. Firms are not subject to VAT and hence should not have been affected by the reform. The test consists of checking whether we observe a similar evolution of electricity demand for SMEs and households, which would then suggests that other factors outside the VAT changes might drive our results. To do so, we re-run regression (3) for both household and business consumers. The results of this test are shown in Table 10 below

Column (1) of Table 10 shows the results of the placebo test. The coefficient for the VAT cut is equal to 0 , indicating that there are no significant changes in electricity demand for SMEs after the VAT cut. During the same period, however, the electricity demand of households increased by $2 \%$ (see column 3 ). Given that only households are subject to the VAT, this evidence suggests that we are capturing the causal impact of the VAT cut on households' consumption. However, the coefficient for the VAT hike is strongly negative and significant. This indicates that the electricity consumption of SMEs has decreased mainly during the period of VAT reinstatement at $21 \%$. This effect is probably due to some other factors affecting SMEs that are unrelated to the VAT change. Indeed, once we account for a time trend in the regression, such effect disappears. These results are shown in column (2), and thus suggests that the electricity consumption of SMEs tended to decline over the period. We also report the estimates for household consumers when including a time trend in electricity consumption. Interestingly, 
we find that our estimate for the VAT cut is unchanged at $2 \%$. This result suggests that our demand estimates do not capture a pre-existing consumption trend in the data. ${ }^{18}$

Table 10

Placebo Test: Impact of VAT Reforms on Business Consumption

\begin{tabular}{lllll}
\hline \hline Variable & $\begin{array}{c}\text { Business } \\
(\mathbf{1})\end{array}$ & $\begin{array}{c}\text { Business } \\
\mathbf{( 2 )}\end{array}$ & $\begin{array}{c}\text { Households } \\
\mathbf{( 3 )}\end{array}$ & $\begin{array}{c}\text { Households } \\
\mathbf{( 4 )}\end{array}$ \\
\hline \hline VAT $_{\text {cut }}$ & $\mathbf{- 0 . 0 0}$ & $\mathbf{- 0 . 0 0}$ & $\mathbf{0 . 0 2 * * *}$ & $\mathbf{0 . 0 2 * * *}$ \\
& $(0.01)$ & $(0.01)$ & $(0.00)$ & $(0.00)$ \\
VAT $_{\text {hike }}$ & $\mathbf{- 0 . 0 5 * * *}$ & $\mathbf{- 0 . 0 1}$ & $\mathbf{- 0 . 0 2 * * *}$ & $\mathbf{0 . 0 1 * * *}$ \\
Auto & $(0.00)$ & $(0.01)$ & $(0.00)$ & $(0.00)$ \\
production & $-0.11^{* * *}$ & $-0.07^{* * *}$ & $-0.15^{* * *}$ & $-0.18^{* * *}$ \\
Degree-Day & $(0.02)$ & $(0.01)$ & $(0.01)$ & $(0.01)$ \\
& $0.04^{* * *}$ & $0.05^{* * *}$ & $0.06^{* * *}$ & $0.07^{* * *}$ \\
Sunlight & $(0.00)$ & $(0.00)$ & $(0.00)$ & $(0.00)$ \\
Price & $-0.07^{* * *}$ & $-0.06^{* * *}$ & $-0.05^{* * *}$ & $-0.04^{* * *}$ \\
(net VAT) & $(0.01)$ & $(0.00)$ & $(0.00)$ & $(0.00)$ \\
\hline \hline Time Trend & 0.04 & $0.07^{* *}$ & $-0.04^{*}$ & -0.02 \\
\hline \hline R-squared & $(0.03)$ & $(0.03)$ & $(0.02)$ & $(0.02)$ \\
\hline \hline
\end{tabular}

Notes: * ** and *** indicate statistical significance at the 0.10, 0.05 and 0.01 level respectively. Standard errors, clustered at the distributor level, are in parenthesis. Control variables also include distributor FE, monthly FE, and their interaction.

\section{Conclusions}

This paper studies the impact of a temporary VAT cut on the Belgian electricity market, which occurred in the period between April 2014 and September 2015. The Belgian government temporarily reduced the VAT rate on electricity prices from $21 \%$ to $6 \%$. We study how such VAT cut affected both the price and demand for electricity. We estimate the VAT pass-through to electricity prices by means of a difference-in-differences analysis. We use the electricity price paid by firms (not subject to VAT) as a control group for the period before and after the temporary VAT cut. The results show that the VAT cut was fully shifted to electricity prices so that households could entirely benefit from the tax reduction. We do not find any asymmetry in tax shifting between the VAT cut to $6 \%$ and the subsequent reinstatement of the VAT to $21 \%$.

\footnotetext{
${ }^{18}$ The coefficient for the VAT hike is positive instead of being equal to -0.02 . However, this is probably because the effect of the VAT increase is fully absorbed by the negative time trend in the last periods of our sample.
} 
We then exploit the exogenous tax reform to estimate the impact of the temporary VAT cut on the electricity demand of Belgian households and get a measure for the demand elasticity. We find that the VAT cut generated a $2.05 \%$ increase in electricity demand and that demand elasticity is equal to 0.12 , with some heterogeneity across Belgian regions. Furthermore, we provide novel evidence about the symmetry in the consumers' response to price cuts and price hikes. That is, consumers are equally sensitive to a price cut and a price hike of a similar extent. This finding has important implications for price-based climate policies, as it indicates that price hikes can be a useful tool in reducing carbon emission due to electricity generation. We also show that consumers reacted immediately to the VAT cut, increasing their demand the next month. This evidence contrasts with the existing literature, suggesting that the tax change was more salient compared to other price changes. 


\section{References}

Alberini, A., \& Filippini, M. (2011). Response of residential electricity demand to price: The effect of measurement error. Energy economics, 33(5), 889-895.

Benedek, D., De Mooij, R. A., Keen, M., \& Wingender, P. (2019). Varieties of VAT pass through. International Tax and Public Finance, 1-41.

Berardi, N., Sevestre, P., Tepaut, M., \& Vigneron, A. (2016). The impact of a 'soda tax' on prices: evidence from French micro data. Applied Economics, 48(41), 3976-3994.

Besley, T. J., \& Rosen, H. S. (1999). Sales Taxes and Prices: An Empirical Analysis. National Tax Journal, 52(2), 157-78.

Boccard, N. \& Gautier, A. (2020). Solar rebound: the unintended consequences of subsidies. CORE Discussion Papers 2020002, Université catholique de Louvain, Center for Operations Research and Econometrics (CORE).

Bureau Fédéral du Plan. (2015). Évaluation de la baisse de la TVA sur l'électricité à usage domestique. Downloaded on 2020 April 12. Available at $<$ https://www.plan.be/uploaded/documents/201507231617290.REP_EVABTWELEK715_11 058_00000003.pdf $>$

Carbonnier, C. (2007). Who pays sales taxes? Evidence from French VAT reforms, 19871999. Journal of Public Economics, 91(5-6), 1219-1229.

Cawley, J., \& Frisvold, D. E. (2017). The Pass-Through of Taxes on Sugar-Sweetened Beverages to Retail Prices: The Case of Berkeley, California. Journal of Policy Analysis and Management, 36(2), 303-326.

Chetty, R., Looney, A., \& Kroft, K. (2009). Salience and taxation: Theory and evidence. American economic review, 99 (4), 1145-77.

DeCicca, P., Kenkel, D., \& Liu, F. (2013). Who pays cigarette taxes? The impact of consumer price search. Review of Economics and Statistics, 95(2), 516-529.

DellaVigna, S. (2009). Psychology and economics: Evidence from the field. Journal of Economic literature, 47(2), 315-72.

Deryugina, T., MacKay, A., \& Reif, J. (2020). The long-run dynamics of electricity demand: Evidence from municipal aggregation. American Economic Journal: Applied Economics, 12(1), 86-114. 
Doyle Jr, J. J., \& Samphantharak, K. (2008). \$2.00 Gas! Studying the effects of a gas tax moratorium. Journal of public economics, 92(3-4), 869-884.

Etilé, F., Lecocq, S., \& Boizot-Szantai, C. (2019). The Incidence of Soft-Drink Taxes on Consumer Prices and Welfare: Evidence from the French " Soda Tax”. PSE Working Papers. Eurostat (2020). Energy (nrg). Energy statistics - quantitis [Data file]. Downloaded on 2020 April 7 (last update: 2020-02-24). Available at <http://ec.europa.eu/eurostat/data/database>.

Fabra, N., \& Reguant, M. (2014). Pass-through of emissions costs in electricity markets. American Economic Review, 104(9), 2872-99.

Gautier, A., \& Jacqmin, J. (2020). PV adoption: the role of distribution tariffs under net metering. Journal of Regulatory Economics, 57, 53-73.

Harding, M., Leibtag, E., \& Lovenheim, M. F. (2012). The heterogeneous geographic and socioeconomic incidence of cigarette taxes: Evidence from Nielsen Homescan Data. American Economic Journal: Economic Policy, 4(4), 169-198.

Hindriks, J., \& Serse, V. (2019). Heterogeneity in the tax pass-through to spirit retail prices: Evidence from Belgium. Journal of Public Economics, 176, 142-160.

Hintermann, B. (2016). Pass-through of CO2 emission costs to hourly electricity prices in Germany. Journal of the Association of Environmental and Resource Economists, 3(4), 857891.

Ito, K. (2014). Do consumers respond to marginal or average price? Evidence from nonlinear electricity pricing. American Economic Review, 104(2), 537-63.

Kenkel, D. S. (2005). Are alcohol tax hikes fully passed through to prices? Evidence from Alaska. American Economic Review, 95(2), 273-277

Kosonen, T. (2015). More and cheaper haircuts after VAT cut? On the efficiency and incidence of service sector consumption taxes. Journal of Public Economics, 131, 87-100.

Labandeira, X., Labeaga, J. M., \& López-Otero, X. (2017). A meta-analysis on the price elasticity of energy demand. Energy Policy, 102, 549-568.

Marion, J., \& Muehlegger, E. (2011). Fuel tax incidence and supply conditions. Journal of public economics, 95(9-10), 1202-1212.

Poterba, J. M. (1996). Retail price reactions to changes in state and local sales taxes. National Tax Journal, 165-176. 
Rapson, D. (2014). Durable goods and long-run electricity demand: Evidence from air conditioner purchase behavior. Journal of Environmental Economics and Management, 68(1), $141-160$.

Sahari, A. (2019). Electricity prices and consumers' long-term technology choices: Evidence from heating investments. European Economic Review, 114, 19-53.

Sexton, S. (2015). Automatic bill payment and salience effects: Evidence from electricity consumption. Review of Economics and Statistics, 97(2), 229-241.

Shrestha, V., \& Markowitz, S. (2016). The Pass-Through of Beer Taxes to Prices: Evidence from State and Federal Tax Changes. Economic Inquiry, 54(4), 1946-1962. 


\section{Appendix}

\section{A.1 Lagged Price Model}

Although we can only observe a limited time frame, we also measure how demand elasticity varies with time. We re-run regression (4) by using monthly lagged prices. We do this for a maximum of 12 months lag and using the full price variation. ${ }^{19}$ The results of this analysis are displayed graphically in Figure A.1.

Figure A.1

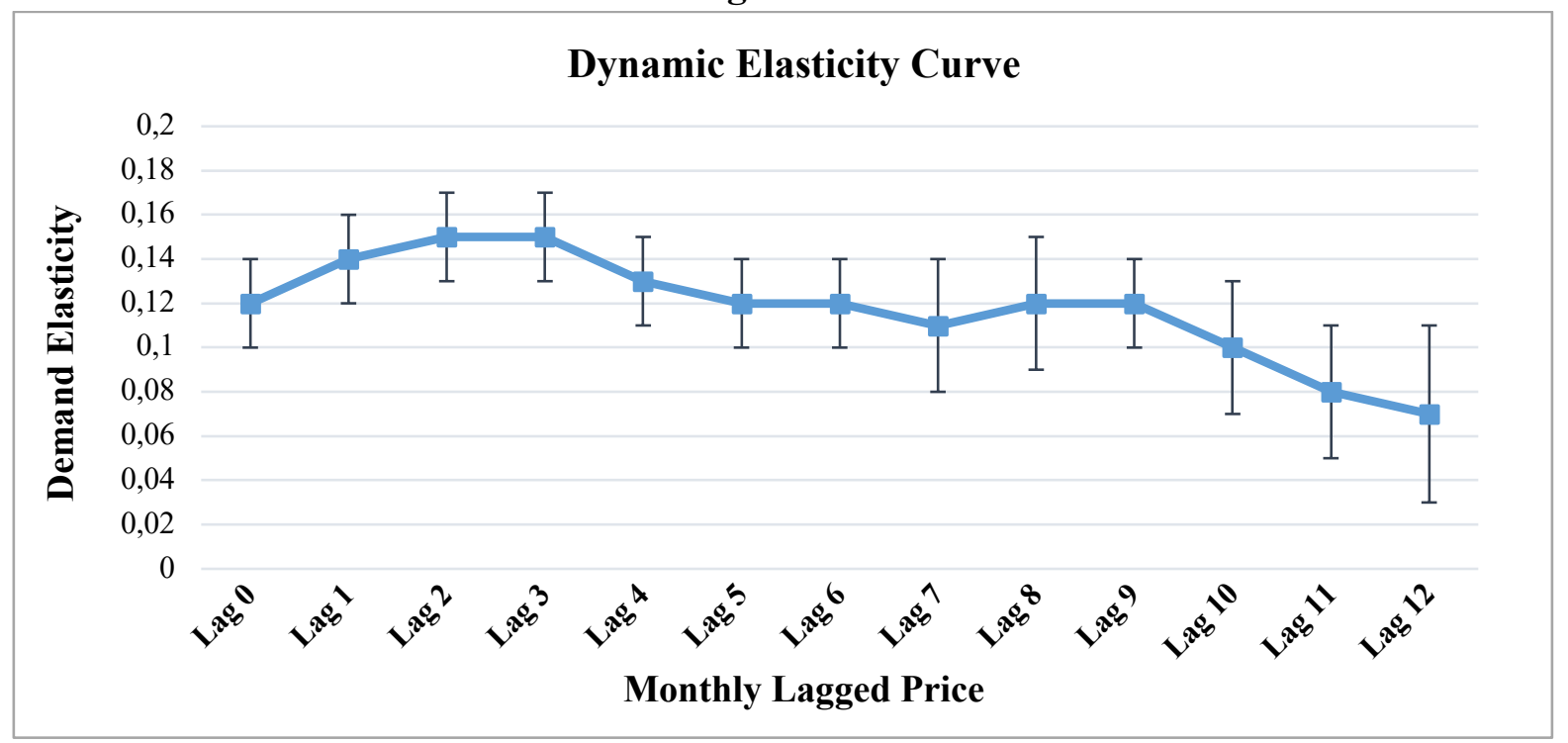

Notes: the curve shows the demand elasticity computed with different lags and their respective confidence interval. Results are obtained by estimating regression (3) with lagged prices instead of the actual monthly price. Each regression for any lag is estimated separately.

Including lagged prices instead of the actual monthly price does not seem to affect our results significantly. Yet, the larger demand response occurs within two and three months from the price change. This evidence suggests that consumers respond quickly to variations in electricity prices. Furthermore, Figure A.1 highlights a slight negative trend of the demand elasticity over time, which indicates that the demand response to price changes tends to decrease over time. This result is in contrast with existing evidence suggesting that demand elasticity is higher in the long-run. As already discussed above, we are identifying the demand elasticity by exploiting large policy shocks to prices that are more salient than a typical change in electricity price. Hence, this can indicate that consumers respond promptly to electricity price changes if they are quite aware of them.

\footnotetext{
${ }^{19}$ Results are similar when using different sources of price variation and are available upon request.
} 